\title{
Changing Risk Exposures of Cross-listed Firms and Market
}

\section{Integration}

\author{
Karen K. Lewis \\ Wharton School, University of Pennsylvania and NBER ${ }^{1}$
}

September 2016

\begin{abstract}
${ }^{1}$ This paper was previously circulated under the titles "Do Foreign Firm Betas Change During CrossListing?" and "Are the Gains from Foreign Diversification Diminishing? Assessing the Impact with Crosslisted Stocks." I thank participants at a number of seminars and conferences for useful feedback. I am especially grateful to Choong Tze Chua, Gangadhar Darbha, Vihang Errunza, Robert Hodrick, Andrew Karolyi, Sandy Lai, and Sergei Sarkissian for comments and to Xiang Fang for excellent research assistance. I acknowledge funding from the National Science Foundation and the Wharton-Singapore Management University Research Center with thanks. Any errors or omissions are my own responsibility.
\end{abstract}

(C) 2016. This manuscript version is made available under the Elsevier user license http://www.elsevier.com/open-access/userlicense/1.0/ 


\begin{abstract}
A standard finding is that risk exposures of companies that cross-list tend to increase against the market in which they list, a change typically associated with a decline in the cost of capital. However, this finding is predicated on the assumption that the home and foreign market co-movements are stable over time. By contrast, another common finding is that risk exposures across market indices have increased over time due to international market integration. In this paper, I ask whether the firm-level findings for changing risk exposures are due to the more general changes in market co-movements. Indeed, for a panel of cross-listed firms in the US, I find that $72 \%$ do not find evidence of breaks in their relationships beyond those derived from their home markets. This finding suggests that the apparent increase in risk exposures for cross-listed firms arises from general market integration trends. Moreover, the remaining $28 \%$ of firms tend to have significant breaks after cross-listing, be younger, and have home markets with lower government regulation.
\end{abstract}


The risk exposure of companies change if they cross-list their equities outside their home market, a change typically associated with a decline in the cost of capital. This finding has been established in a large literature on cross-listing. ${ }^{1}$ An early view in this literature was that the lower cost of capital associated with cross-listing was due to circumvention of restrictions that impeded international market integration. ${ }^{2}$ Nevertheless, subsequent studies recognized that the cost of capital effect alone could not be a major driver in explaining the pattern of cross-listing both across countries and over time. ${ }^{3}$

An approach common to these studies may affect the interpretation of these results, however. Specifically, the company risk exposures are evaluated under the implicit assumption that the relationship between international equity markets is stable over time. This assumption stands in contrast with a number of papers that show that international equity market co-movements have changed over time, potentially due to a general trend toward integration. ${ }^{4}$ This observation leads to the question: do the changing risk exposures reflect company-level shifts or more general market integration trends across countries? Moreover, do these risk exposures change at the same time as the cross-listing event or do they change when their home market becomes more integrated in world markets? Answering these questions clearly alters the interpretation of the decline in cost of capital by cross-listed firms. If the decline is due to general market integration, then the cost of capital is also reduced for other firms that do not cross-list, providing further evidence that other factors may motivate the cross-listing decision.

In this paper, I address these important questions by analyzing the history of foreign firms

\footnotetext{
${ }^{1}$ See for example, Foerster and Karolyi (1999), Miller (1999), Errunza and Miller (2000), and Sarkissian and Schill (2004).

${ }^{2}$ Karolyi $(1998,2006)$ provide reviews of this literature and describe the early conventional wisdom about the cost of capital.

${ }^{3}$ In particular, abnormal returns tend to increase around cross-listing for firms that are substantially integrated in world markets and not all firms that would appear to benefit from a lower cost of capital do so. For articulation of these arguments as well as others, see the discussion in Stulz (1999) and in Karolyi (2006).

${ }^{4}$ Changing risk exposures across international equity markets due to market integration have been noted in a large literature. See, for example, Bekaert and Harvey (1995) and Christoffersen, Errunza, Jacobs, and Langlois (2012).
} 
that are listed on U.S. exchanges at a point in time. ${ }^{5}$ Specifically, using Bai and Perron (1998) break date analysis, I test whether the betas of these firms against the U.S. market changed and, if so, ask by how much and on what date. ${ }^{6}$ Consistent with the literature, I find that the returns data for most cross-listed companies reject the hypothesis that their betas against the U.S. market have been constant over time. Surprisingly, however, the hypothesis that these breaks are due to changes in the relationship between the firm's home market and the U.S. market cannot be rejected for $72 \%$ of these firms. This result suggests that much of the evidence for changing risk exposures of cross-listed firms found in the literature may arise from changing risk exposures between the U.S. and home markets, not from the firms themselves.

I then evaluate these changing risk exposures in light of the related market integration literature in several ways. First, the firm-level estimates are combined to construct implied market betas over time, showing a tendency for increased synchonicity over time. I then decompose and analyze this increase for cross-listed stocks and non-cross-listed stocks across the home markets, showing that this effect is not driven by cross-listed firms alone. Lastly, the break dates for emerging markets are compared with estimated liberalization dates found in the literature. In all these cases, the estimates appear to be consistent with standard findings on market liberalization and integration.

These results raise an additional question: What is different about the remaining $28 \%$ of crosslisted firms that do show evidence of changing betas independently of their home markets? Using multinomial logit regressions across the cross-section of firm, I find a striking result. The breaks in the betas of these firms generally occur statistically significantly after the cross-listing event. Moreover, these firms tend to be younger and have home markets with less stringent governmental restrictions, consistent with the view that US investors update their views about these cross-listed

\footnotetext{
${ }^{5}$ While this paper focuses on cross-listed stocks in the U.S. market, this phenomenon also tends to hold in other countries. See the cross-listing literature described in Section 1.

${ }^{6}$ Although this analysis estimates discrete changes at particular dates for individual firms and their home countries, the results are similar when the exposures change more gradually, as shown in Section 4.
} 
firms only after some learning time. ${ }^{7}$

To illustrate primary features of the analysis below, Figure 1 plots several possible outcomes from the break date estimates with the examples of the Swedish market and four cross-listed companies from Sweden arrayed on the horizontal axis and the year dates on the vertical axis. As the figure shows, the estimated break date for betas of the Swedish market returns against the U.S. market is September 1997 with confidence interval bands plus or minus about seven months. The Swedish company examples illustrate a range of outcomes for estimated break dates. For Electrolux, the confidence interval includes that of the break in the Swedish market. ${ }^{8}$ However, Ericsson has an earlier break date in late 1990 and would therefore tend to reject a common change with the market. Volvo has two apparent breaks, one in the early 1990s and another in the early 2000s, but neither overlap with the overall Swedish market, thereby also rejecting a common change. Finally, Telia Sonera is a company with no significant evidence of a break in equity return behavior, and therefore has no break point estimate.

While this figure illustrates a range of dates alone, testing for the relationship between markets and firm-level risk exposures requires a joint analysis of beta estimates and dates. For this purpose, I use a factor model to study whether estimated changes in firm-level betas are generated by changes at the market level. Consistent with many studies of market-level integration, I find that the betas, as well as the correlations, in country returns have increased over time. Figure 2 illustrates some potential evolutions of firm-level betas for three different company examples, subsuming the standard errors for clarity. Specifically, the figures depict the estimated betas over time with shifts in the estimates on the break date and starred triangles to indicate confidence intervals around the

\footnotetext{
${ }^{7}$ Canadian firms also tend to experience a break after cross-listing but, as shown below, the changes in betas from these firms appear to be explained by the long period of integration between the US and Canadian markets. Similarly, Carrieri, Errunza and Hogan (2007) note the high integration between the two markets.

${ }^{8}$ Although I describe a simple comparison between the point estimates and their confidence intervals in the introduction, the analysis below provides a joint test across market and firm return betas that incorporates sampling error in estimated betas across markets and firms.
} 
break dates. Figure 2a and Figure $2 \mathrm{~b}$ show a pattern of increasing betas against the US for two firms, respectively, Gerdau, a Brazilian company, and James Hardie, an Australian company. By contrast, Figure 2c illustrates that for another Brazilian company, Vale Do Rio, the betas decrease and thereby move in the opposite direction from the rest of the Brazilian market.

Conducting the joint tests for all firm and market return pairs delivers the results noted earlier that only $28 \%$ of the cross-listed firms show evidence of betas that change independently of their home markets. I then further ask: Do breaks in cross-listed firm betas occur within a window around cross-listing as presumed in the cross-listing literature or at some other time? This question can be posed as a hypothesis test that the cross-listing date is within the confidence interval around the break and, further, that the movement in betas is in the direction found in the literature.

Returning to Figure 2, estimates for the three companies illustrate some of the potential answers. With the cross-listing date marked as a box on the beta estimate, Figure 2a shows that the crosslisting date for Gerdau is indeed within the estimated break date interval as would be picked up with standard event studies. By contrast, Figure 2b graphs James Hardie's beta showing a crosslisting date earlier than the confidence interval of the break date. And Figure 2c demonstrates that Vale Do Rio delivers the opposite case with a cross-listing after the estimated confidence interval. With this framework and the sample of all cross-listed firms, I then test for the hypothesis that cross-listing occurs within the confidence interval of breaks, or before or after.

The paper is organized as follows. Section 1 describes the related international finance literatures. Section 2 sets up the empirical framework and provides initial break-date results by firms. Section 3 decomposes the changes in exposures into those between firms and markets and into those between the markets themselves. Section 4 relates the evidence on the estimated breaks to studies of market integration and cross-listings and considers various robustness measures. Section 5 provides concluding remarks. 


\section{Related International Finance Literature}

The results in this paper are related to two strands of the international finance literature. The first strand studies the causes and effects of cross-listing events on returns and their importance for market and firm-level integration. The second strand of related international finance literature concerns integration at the general equity market level. A large body of research has studied both of these areas. ${ }^{9}$ I focus here only upon research most related to the questions addressed in this paper concerning the risk exposures of cross-listed firms and their markets.

The first strand of literature typically finds that the betas of firms change after cross-listing. As surveyed by Karolyi $(1998,2006)$, studies in this area examine risk exposures in order to gauge the effects of cross-listings on a firm's returns. These studies typically regress the excess returns of cross-listed firms on their home country market as well as that of the host listing market or, alternatively, some measure of the world market. A common finding is that the betas of these firms increase in the host market and either decrease or are unchanged in the home market (e.g., Foerster and Karolyi (1999), Miller (1999), Errunza and Miller (2000), and Sarkissian and Schill (2004). $)^{10}$ In the analysis below, I corroborate this general finding but, further, decompose whether the change is due to the company or its home market.

The second strand of related international finance literature concerns integration at the general equity market level. A large literature has demonstrated that markets are not fully integrated, but instead demonstrate some international segmentation. ${ }^{11}$ As with the cross-listed firm analysis, risk

\footnotetext{
${ }^{9}$ For surveys of the cross-listing literature, see Karolyi $(1998,2006)$. Examples of surveys of the market integration literature include Lewis (2011) and Coeurdacier and Rey (2012).

${ }^{10} \mathrm{~A}$ number of explanations have been evaluated for the decision to cross-list and its consequences on pricing. These explanations include market segmentation (e.g., Karolyi (1998), Stulz (1999)), perceptions due to legally binding or more stringent disclosure requirements (e.g., Coffee ( 2002), Doidge, Karolyi, and Stulz (2004), Hail and Leuz (2009)), and differences in information flows due to issues such as accounting choices, tax-haven status, product sales and geographical proximity (e.g., Pagano, Roell, and Zechner (2002), Sarkissian and Schill (2004)). In this paper, I take an approach that is agnostic about the motivations for cross-listings and instead examine the firm-level changes in risk sensitivities without conditioning on cross-listing dates.

${ }^{11}$ For instance, Dumas and Solnik (1995) show that the international CAPM based upon market integration does not hold in the data. In a different vein, Errunza and Losq (1985) develop a model of "mild segmentation," with
} 
exposures of returns are often used to study changes over time. Typically, these studies find an increase in the risk exposures of country market returns with the global market, an observation often associated with market integration as can be seen in studies such as Christoffersen, Errunza, Jacobs, and Langlois (2012) and Pukthuanthong and Roll (2009). As these and other studies have pointed out, a more formal definition of financial market integration would be that risk carries the same price in each market. Clearly, this definition is not equivalent to an increase in risk exposures. Nevertheless, since rising risk exposures are often casually referenced as increased market integration, I use this informal terminology below.

Emerging market integration and liberalization studies have also focused upon changes in risk exposures. For example, Bekaert and Harvey (1995,2000), Henry (2000), Bonser-Neal, Brauer, Neal, and Wheatley (1990), and Kim and Singal (2000) relate liberalizations from these countries to effects on costs of capital, and in some cases the dates of the first ADR introduction. Bekaert, Harvey, and Lumbsdaine (2002) use information between ADRs and market fundamentals to help date estimated liberalization dates and compare them to economic events. Given the documented interaction between changing betas and liberalization, I verify in Section (4.2) that my estimated market break dates for emerging markets correspond with both official liberalization and estimated integration dates in the literature.

Taking these two strands of literature together suggests that risk exposures tend to be increasing over time, both for cross-listed firms and for country markets relative to the world. In the next section, I begin to analyze the connection between these two observations.

evidence found in Errunza, Senbet and Hogan (1998) and Carrieri, Errunza, and Hogan (2007). Other papers finding incomplete integration include Dumas, Harvey, and Ruiz (2003), Bekaert, Harvey, Lundblad, and Siegel (2011), Carrieri, Chaieb, and Errunza (2013), and Lewis and Liu (2015). 


\section{Do Cross-listed Firm Betas Change Over Time?}

This section provides the groundwork for the analysis on foreign firm break dates by describing the data, empirical framework, and initial break date estimates in the return processes.

\subsection{Data}

To analyze potential changes in foreign stock return betas, I require a set of foreign company returns with a sufficient history after U.S. cross-listing. For this purpose, I choose weekly dollar returns on foreign companies that are listed on the NYSE and NASDAQ. Exchange-traded foreign companies are targeted because, according to the literature, these stocks are the most liquid and have the largest pricing effects, and also comprise most of the trading volume of cross-listed stocks. To mitigate the possibility that changes in stock return behavior simply arise from capital raising, I restrict the study to foreign listings on exchanges that are not accompanied by equity issuances (e.g., ADR Level 2). ${ }^{12}$ In addition, July 2004 is picked as the inclusion date since it implies at least five years of data before the financial crisis. ${ }^{13}$ The time period begins either at January 1970 or at the earliest date of availability thereafter and ends in October 2009. Notably, the set of stocks after 2004 is relatively stable since less than $1 \%$ of companies in this sample were delisted by the end of the sample. Companies without a return series history in their home markets or with insufficient numbers of observations were excluded. The number of companies after applying these filters is 576. I use the Data Stream Total Return indices and Total Market Return indices to calculate the company returns and the market index returns, respectively. All returns are transformed into excess returns by subtracting the weekly T-bill rate. Cross-listing dates are measured by the date

\footnotetext{
${ }^{12}$ For example, Foerster and Karolyi (1999) find that the post-listing price decline for capital raising firms is not as large as the other cross-listings.

${ }^{13}$ Similarly, Sarkissian and Schill (2009) choose 1999 because they focus upon long run returns after cross-listing up to ten years. Sarkissian and Schill (forthcoming) also consider foreign listings in all world stock exchanges in 2003 and 2006 .
} 
when the company was listed on the current exchange, either the NYSE or NASDAQ. ${ }^{14}$

Table 1 provides summary information about this data set. Panel A reports the break-down of firms across exchanges. NYSE has 380 foreign companies with home markets in 39 different countries. By contrast, 196 foreign companies that are domiciled in 28 countries list on NASDAQ. The total number of foreign countries represented on the two exchanges is 42. Finally, Panel A shows that the foreign companies listed on NYSE are generally older than those on NASDAQ. The average number of observations across firms on the NYSE is 1092, or about 21 years, while that same average across firms on NASDAQ is 862 , or about 17 years.

Panel B of Table 1 breaks down the information by the home country of the company. The first column gives the date at which the market index data begin for each country, ranging from January 2, 1970 for the U.K. to July 8, 1994 for Brazil. The columns to the right provide more information about the composition of the foreign company presence on each exchange. The home country with the largest number of cross-listed companies is Canada, followed by the United Kingdom. Emerging markets generally have the fewest foreign companies on the exchanges and lower average numbers of observations.

\subsection{Asset Pricing Framework}

As a benchmark for conducting event studies, the cross-listing literature often uses a two-factor model that depends upon both the company's home market and the cross-listed market, in this case the US market. This relationship is given by: ${ }^{15}$

$$
r_{t}^{i \ell}=\alpha^{i \ell}+\beta^{i \ell} r_{t}^{\ell}+\beta^{i u} r_{t}^{u}+e_{t}^{i \ell}
$$

\footnotetext{
${ }^{14}$ Note that this event benchmark biases against my finding below that the cross-listing date tends to fall before the estimated break date. If I were to use the announcement date or the earliest ADR listing date in the US, these events would be even earlier than the estimated breaks and reinforce my finding.

${ }^{15}$ Other benchmarks include a domestic CAPM. For example Sarkissian and Schill (2009) consider not only the domestic CAPM and equation (1), but also estimate a third model that substitutes the world market return for the foreign market.
} 
where $r_{t}^{i \ell}$ is the excess return at date $t$ on the equity of company $i$ that has a home market of country $\ell, \alpha^{i \ell}$ is a constant parameter, $r_{t}^{\ell}$ and $r_{t}^{u}$ are the excess home market returns of the crosslisted company and the US markets, respectively, and $\beta^{i \ell}$ and $\beta^{i u}$ are their factor loadings. ${ }^{16}$ As described above, standard findings in the literature are that $\beta^{i \ell}$ and $\beta^{i u}$ change upon cross-listing. All returns are in excess of the investor's risk free rate. Since all the analysis below requires excess returns, these variables are simply called "returns" throughout the rest of the paper.

Clearly, the two factor model in equation (1) focuses upon the relationship between firm returns and those of their home markets and the U.S. By contrast, the market integration literature noted in Section 1 often focuses upon the relationships between the returns on market indices and how these risk exposures may have changed over time. Implicitly, time-variation in betas across country level returns could also generate apparent instability in the estimates of $\beta^{i \ell}$ and $\beta^{i u}$, even if the company returns are stable relative to each market. For example, consider a standard world CAPM, often used to capture the joint behavior of markets:

$$
r_{t}^{\ell}=\alpha^{\ell}+\beta^{\ell} r_{t}^{u}+u_{t}^{\ell}
$$

where the world market return has been substituted out using the world CAPM for the U.S. market return. ${ }^{17}$ Further substituting the country relationship in equation (2) into the company return framework in equation (1) implies:

$$
r_{t}^{i \ell}=\alpha^{i \ell}+\beta^{i \ell}\left[\alpha^{\ell}+\beta^{\ell} r_{t}^{u}+u_{t}^{\ell}\right]+\beta^{i u} r_{t}^{u}+e_{t}^{i \ell}=a^{i \ell}+b^{i \ell} r_{t}^{u}+\varepsilon_{t}^{i \ell}
$$

\footnotetext{
${ }^{16}$ While the cross-listing literature has focused upon the parsimonious two factor model, there may be more factors that are important for explaining international stock returns. For example, Karolyi and Wu (2012) examine a multifactor model of international returns and note the importance of a hybrid model that depends upon "global" and "local" factors. Similarly, Bekaert, Hodrick, and Zhang (2009) show that a factor model that includes additional global and local Fama-French factors best explains the returns of companies that comprise the MSCI World Index. Therefore, as a robustness check, I also estimated a three factor model including industry effects, finding qualitatively similar results.

${ }^{17}$ This equation obtains by specifying each country's return as a CAPM against the world market and then substituting out the world return using the US market return equation.
} 
where $b^{i \ell}=\beta^{i \ell} \beta^{\ell}+\beta^{i u}$, and similarly, $a^{i \ell}$ and $\varepsilon_{t}^{i \ell}$ incorporate the combined interactions of the international market returns and the company returns. ${ }^{18}$ Thus, if the relationship between the foreign markets and the US market change over time so that $\beta^{\ell}$ varies, the sensitivity of company returns on the U.S. captured by $b^{i \ell}$ will appear to be unstable, even if $\beta^{i \ell}$ and $\beta^{i u}$ are not.

In this section, I begin by studying the standard two-factor model in equation (1) to ask whether the data and framework analyzed here corroborate the standard finding that risk exposures appear to change for cross-listed firms and that these changes represent increased exposure to the U.S. market. In Section 3 below, I test more formally whether these differences arise from market level changes as in equation (2) or firm level changes in equation (1) or both.

\subsection{Parameter and Break-date Estimator}

Studies of cross-listing events have considered shifts in pricing parameters at the time of crosslisting. I therefore require an empirical strategy that allows the factor loading parameters to shift discretely on given dates. For this purpose, the analysis below uses the break date estimator developed by Bai and Perron (1998), hereafter BP. Although I focus upon discrete changes in risk exposures to relate to the cross-listing literature, Bai and Perron (2003a) show how the estimator can also be interpreted as a more gradual change in parameters that cumulates into a significant change at a given time. In Subsection 4.5 below, I consider the sensitivity of this assumption using a modification that explicitly considers more gradual changes.

The BP estimator requires specifying a maximum number of breaks in the parameters, $m$, a value that will be estimated in the empirical analysis below. To economize on notation for this description, I subsume the superscripts in equations (1) and (2), rewriting the asset pricing

\footnotetext{
${ }^{18}$ In particular, $a^{i \ell} \equiv \alpha^{i \ell}+\beta^{i \ell} \alpha^{\ell}$ and $\varepsilon_{t}^{i \ell} \equiv \beta^{i \ell} u_{t}^{\ell}+e_{t}^{i \ell}$.
} 
relationship generally as:

$$
r_{t}=\delta^{\prime} f_{t}+e_{t}
$$

where $r_{t}$ is the asset return series, $e_{t}$ is the residual, $\delta$ is the parameter vector and $f_{t}$ is a vector of factors rewritten to include a constant as the first factor.

Consider now $m$ potential shifts in the parameter vector $\delta$, so that the model in equation (4) can be rewritten as:

$$
r_{t}=\delta_{\tau}{ }^{\prime} f_{t}+e_{t, \tau}
$$

where $\delta_{\tau}$ is the fixed parameter for each period $\tau, \tau=1, \ldots, m+1$ on the intervals implied by: $t=\left\{1, \ldots, T_{1}, T_{1}+1, \ldots, T_{2}, T_{2}+1, \ldots, T_{3}, \ldots, T_{m}, \ldots, T\right\}$ for $T_{0}=0$ and $T_{m+1}=T$. For instance, $\tau=1$ corresponds to the subperiod $t=1, \ldots, T_{1}, \tau=2$ corresponds to the subperiod $t=T_{1}+1, . ., T_{2}$, etc. Similarly, $e_{t, \tau}$ is the residual vector for a fixed distribution over these intervals.

BP show that unknown breakpoints can be estimated consistently by minimizing over the sum of squared residuals for all possible partitions of the data into $m+1$ different intervals. In other words, $T_{1}, T_{2}, \ldots, T_{m}$ can be consistently estimated by solving the following minimization:

$$
\left\{\widehat{T}_{1}, \widehat{T}_{2}, \ldots, \widehat{T}_{m}\right\}=\underset{T_{1}, T_{2}, \ldots, T_{m}}{\arg \min }\left[\sum_{\tau=1}^{m+1}\left(\sum_{t \in\left\{T_{(\tau-1)}, \ldots, T_{\tau}\right\}}\left[r_{t}-\delta_{\tau}^{\prime} f_{t}\right]^{2}\right)\right]
$$

$\mathrm{BP}$ also derive the limiting distribution of these break point estimates including confidence intervals on the breakpoint estimates, as previously illustrated in Figure 1.

While the estimation of the break dates requires minimizing the sum of squared residuals for all possible $m$ partitions of the data, Bai and Perron (2003b) show that the estimator can have poor properties when the minimal length of the partition becomes too small. The reason is intuitively clear - finer partitions of the intervals imply fewer observations and, therefore, less precise 
estimates. Bai and Perron (2003b) therefore propose constraining the minimal length of any partition segment $\tau$ in equation (6). They define this minimal length as $h \equiv \min \left(\widehat{T}_{(\tau-1)}+1, \ldots, \widehat{T}_{\tau}\right) \forall \tau$ and specify a percentage "trimming" constraint $\varepsilon$ as a percentage of the sample size according to: $\varepsilon=h / T$. To be conservative, I set $\varepsilon=15 \%$ for the primary reported results below. ${ }^{19}$

To see how this relationship translates into the asset return relationships, consider for example the two-factor model in equation (1). Rewriting this equation in the form of equation (5) yields:

$$
r_{t}^{i \ell}=\delta_{\tau}^{i} f_{t}^{\ell}+e_{t, \tau}^{i \ell}=\alpha_{\tau}^{i \ell}+\beta_{\tau}^{i \ell} r_{t}^{\ell}+\beta_{\tau}^{i u} r_{t}^{u}+e_{t, \tau}^{i \ell}
$$

with number of breaks given by $m^{i}$ for each company $i$. Then, the set of parameter vectors for each subperiod $\tau$ is given by: $\delta_{\tau}^{i}=\left\{\alpha_{\tau}^{i \ell}, \beta_{\tau}^{i \ell}, \beta_{\tau}^{i u}\right\}, \tau=1, \ldots, m^{i}+1$.

To analyze the potential for breaks, I analyze each return $i$ using equation (7) in the following two steps. First, I test for the number of breaks, $m^{i}$. Second, I search over all possible combinations of the break dates in order to minimize the sum of squares given by the objective in equation (6). This minimization consequentially generates estimates of break dates: $\left\{\widehat{T}_{1}^{i}, \widehat{T}_{2}^{i}, \ldots, \widehat{T}_{m}^{i}\right\}$ and the corresponding set of parameter vectors, $\delta_{\tau}^{i}$, for $\tau=1, \ldots, m^{i}+1$.

Note that since I conduct analysis on each stock return series separately, the number of parameter shifts, $m^{i}$, differ by company. This analysis also includes as a possibility that $m^{i}=0$; that is, no breaks. Moreover, the variance of the residual is generally allowed to change over subperiods and across countries. The standard errors are also corrected for general conditional heteroskedasticity (White (1980), Andrews (1991)).

\footnotetext{
${ }^{19}$ In Monte Carlo simulations, Bai and Perron (2003a,b) find that the maximal value of $m$ for $\epsilon=0.15$ is 5 . Since $m$ is 4 or less in all the analysis in this paper, my choice of $\varepsilon$ at $15 \%$ appears relatively conservative. However, I describe similar results with $\varepsilon=5 \%$ in Section 4 , albeit with somewhat more frequent breaks.
} 


\subsection{How Many Breaks Are In Firm Betas?}

Table 2 reports the results of break-date tests for each of the company return regressions in equation (7). The first row in Panel A shows the results for the set of cross-listed companies. This panel clearly shows that breaks in the relationship between the company returns and the market returns are important. The first three columns report the proportions of the companies rejecting the hypothesis of no breaks versus $m^{i}$ breaks using the so-called "sup F" test. This test finds the highest $\mathrm{F}$ statistic for $m^{i}$ breaks by considering all the different partitions of subsamples in equation (6), subject to the minimum length restriction, $h$. The first column shows that the hypothesis of no break against the alternative of at least one break is rejected for $77.1 \%$ of the companies at a $5 \%$ marginal significance level (MSL) and even $67.6 \%$ at a $1 \%$ marginal significance level. As the second and third columns show, these proportions generally become higher when allowing for more breaks.

While Bai and Perron (2003a,b) advocate using the supF test with given numbers of breaks, they acknowledge that there are circumstances in which the results might be deceptive. ${ }^{20}$ For this reason, they also suggest testing the hypothesis of no breaks against an unknown number of breaks. The last two columns of Panel A report the proportion of companies with stock returns that reject this hypothesis using two versions of the "Double Maximum" (D Max) test. The "WD Max" test weights the tests of individual breaks such that the marginal p-values are equal across values of $m$. By contrast, the "UD Max" test weights all values of $m$ equally. Again, the table shows the proportion of companies with returns that reject the hypothesis of no break is high, and above $70 \%$ even at a $1 \%$ MSL.

Panel B of Table 2 provides summary evidence for the number of companies that reject the sequential "supF test" at the MSL of $5 \%$. In this test, a sequential procedure estimates each

\footnotetext{
${ }^{20}$ For example, the test will underestimate the number of breaks for a regime switching model in which the parameters switch back to an initial regime.
} 
break one at a time, and estimation stops when the $\sup F(\tau+1 \mid \tau)$ test is no longer significant at the given marginal significance level. To identify $m^{i}$, I conduct sequential SupF tests for each company, allowing up to four subperiods. ${ }^{21}$ The first column of Panel B reports the proportion of the companies that reject the hypothesis of zero breaks. The last three columns of Panel B report the proportion of companies that show evidence of one break, two breaks and three breaks, respectively, in their stock returns.

The row marked "Cross-Listed Firms" in Table 2 Panel B shows that $77.2 \%$ of these firms reject the hypothesis of "No Breaks." Thus, as noted in Panel A, these firms indeed have a tendency for breaks in their beta estimates. Also, as the numbers show, cross-listed companies with one break make up about $55 \%$ of the cross-listed company cases, while those with evidence of 3 breaks are fewer at only $10.7 \%$.

Although these findings corroborate the results in the literature noted earlier that risk exposures of cross-listed companies change over time, the betas of U.S. companies may also have changed over time. Therefore, as a benchmark, the second row in Panel B shows these same estimates for a set of 573 U.S. companies matched to the cross-listed company data set according to market value, age, and listing on NYSE versus NASDAQ. As the numbers show, 19.7\% of the U.S. companies also reject the hypothesis that betas do not change. Although this percentage is larger than the $5 \%$ that would be expected based upon the MSL of the test in the absence of breaks, the proportion is clearly smaller than the cross-listed firms. The row also shows that almost all of these U.S. firms have only one break. Only $4 \%$ of the firms show evidence of two breaks and there is no evidence of three breaks. Overall, cross-listed firms exhibit more likelihood of breaks as well as a greater number of breaks.

The literature has generally found that betas on the host market rise after cross-listing, with

\footnotetext{
${ }^{21}$ As will be shown below, the company returns show little evidence of more than three breaks, so imposing this maximum number of breaks seems fairly unrestrictive.
} 
more mixed effects in the home market. To evaluate this possibility in the present data, I calculate the equally-weighted and market-weighted averages of changes in the betas for the period before cross-listing versus afterwards. Unlike the standard event study analysis, the changes in betas need not occur at the same time as cross-listing. Therefore, to address how betas change before and after cross-listing, I sort the parameters into periods before, during and after cross-listing dates. In the case of multiple breaks, there may be some firms with different beta estimates in all three periods; i.e., before, during, and after. In these cases, I provide an alternative measure of the "after" beta estimate that excludes the confidence interval specific to each firm around the cross-listing period.

Table 2, Panel C reports the portfolio-weighted means before cross-listing for the home market beta labeled $\beta^{i \ell, B e f o r e}$, and the U.S. market beta labeled $\beta^{i u, B e f o r e}$. It also gives the portfolioweighted difference between the estimated parameters in the confidence interval after cross-listing relative to those before cross-listing. To calculate these statistics, I first array the beta coefficients into bins depending upon whether these estimates are before listing, $\beta^{\text {iu,Before }}$, or after cross-listing $\beta^{i u, A f t e r}$, and then calculate the changes given under the column labeled $\beta^{i u, A f t e r}-\beta^{i u, B e f o r e}$. I also consider an alternative using parameter estimates for the confidence interval around cross-listing. These results are reported in the column labeled $\beta^{i u, D u r i n g}-\beta^{i u, B e f o r e}$.

A basic pattern is clear from these estimates. For both the Market-Weighted and EquallyWeighted portfolios, the average U.S. betas increase after listing, whether measured from an equallyweighted average as in the literature or a market-weighted average. By contrast, the change in the home market beta is more modest than the U.S. beta changes, and is even slightly negative at -0.005 for the Equally Weighted portfolio case. These results are consistent with the general findings in the literature noted earlier that betas against the host market tend to increase after cross-listing, but betas against the home market are more mixed, and sometimes are even negative.

Table 2, Panel D reports some summary information about the companies that reject the 
hypothesis of No Breaks at the 5\% MSL. I call these companies "Breakers" and those that do not reject the hypothesis "Non-Breakers." The first column shows that the proportion of Breakers among the Developed countries at $76.2 \%$ are about the same as the proportion among the Emerging countries at $79.4 \%$. On the other hand, firms on NYSE are somewhat more likely to be Breakers than those on NASDAQ. Moreover, Breakers tend to be somewhat older at 1,063 weeks and have a larger market cap at about 8.3 billion dollars.

\subsection{The Relationship Between Cross-listing and Break Dates}

Breaks in the risk exposures of firms lead to various possibilities about their timing relative to the cross-listing date. Firms may choose to list in markets in which they have similar risk characteristics. $^{22}$ If so, they may experience a break in their risk exposures before cross-listing. Alternatively, the cross-listing event may itself generate a structural break as investors in the new market begin to price this new asset with which they now have greater access. In this case, cross-listing would be within the confidence interval of the break. Finally, investors may need time to learn about the new firm after cross-listing so that the cross-listing date occurs before the break confidence interval.

To consider these possibilities, the companies are sorted according to whether their cross-listing date was before the first Break ("< Break 1"), within the confidence interval of the first break ("=Break 1"), after the first Break (">Break 1"), within the confidence interval of the second break, if any ("=Break 2"), after the second break, if any ("> Break 2"), and after or during the third break. Table 2 Panel D reports information about the sorted firms under these headings, respectively, omitting the last grouping due to small sample size.

Several patterns emerge. First, the initial row labeled "Total Share" shows that $66 \%$ of the Breakers have a cross-listing date that occurs before the first break confidence interval. Second, the

\footnotetext{
${ }^{22}$ For a discussion of this channel, see Baruch, Karolyi, and Lemmon (2007).
} 
proportion of companies with cross-listing dates before the first break date is similar for companies domiciled in Developed versus Emerging countries and on NYSE versus NASDAQ. Third, the firms with cross-listing dates before the first break date tend to be younger with an average age of 886 weeks. I investigate these relationships in more detail in Section 3.

Figure 3 summarizes these relationships by combining the proportion of firms into three groups: (a) those with cross-listing dates before the first break, (b) those with cross-listings within a confidence band of any of the three breaks, and (c) those with cross-listing after the confidence band of any of the three breaks. Figure 3a depicts the proportion for companies with home markets in Developed countries as well as those from Emerging countries. Figure 3b provides the same information but for the proportion of companies with home markets sorted by continents, showing a similar pattern.

Overall, this evidence suggests that the majority of the foreign companies with cross-listed stocks had return betas against the United States market that changed during their history, a finding consistent with the literature. However, this analysis ignores any potential effects due to changes in the relationship between the U.S. market and the companies' respective home markets, an issue I examine next.

\section{Are Changing Firm Betas Due to Country Market Betas?}

The previous section found that the returns of cross-listed firms show evidence of breaks in the estimated betas against the home and host country, as presumed in the literature. However, the betas of these firms against the US market may also increase due to increases between the home and host market, as found in the market integration literature. If so, the relationship found above may not be due to the firm-level relationships, but rather to market-level relationships.

To understand this possibility, suppose that there is instability in the market-level relationship 
between the US and each foreign market in equation (2). Rewriting this relationship to allow for possible breaks implies:

$$
r_{t}^{\ell}=\alpha_{\varsigma}^{\ell}+\beta_{\varsigma}^{\ell} r_{t}^{u}+u_{t, \varsigma}^{\ell}, \text { for } \varsigma=1, \ldots, n^{\ell}+1
$$

where the subscript $\varsigma$ denotes subperiods with stable parameters between the country market returns and $n^{\ell}$ is the number of breaks between the US and country $\ell$. Clearly, substituting these parameters into the firm return equation (3) above, indicates that the firm level parameters will

appear to shift even if the company betas, $\left\{\beta^{i \ell}, \beta^{i u}\right\}$, are stable. Therefore, in this section, I first estimate equation (8) and then condition on these estimates to recover the implied effects on company betas to determine whether the observed instability is due to market level changes.

\subsection{Do Market Return Betas Change Over Time?}

Table 3 reports the results of break tests based upon the country regressions in equation (8). The results in Panel A indeed show that breaks in the relationship between the US and foreign markets are important. The first three columns report the proportions of the 42 country index returns that reject the hypothesis of no breaks versus the hypothesis of $m$ breaks using the "sup F" test. The first column of Table 3A shows that the hypothesis of no break against the alternative of at least one break is rejected for $83 \%$ and $81 \%$ of the country indices at a $5 \%$ and $1 \%$ marginal significance level, respectively. These proportions generally become higher when allowing for $m=2$ and $m=3$, respectively. The last two columns report proportions of countries ranging from $83.3 \%$ to $90.5 \%$ that rejected no breaks using the "WD Max" and the "UD Max" tests.

Panel B of Table 3 summarizes the distribution of the number of breaks estimated for each country using the sequential SupF test at the 5\%, and 1\% MSLs. The first column of Panel B reports the proportion of the countries that rejected the hypothesis of zero breaks while the last three columns of Panel B report the proportion of countries that show evidence of one break, two 
breaks and three breaks. As the evidence shows, countries with one break make up the majority of the cases ranging from $74 \%$ at the $5 \%$ MSL to $82 \%$ at the $1 \%$ MSL.

Given the evidence for country breaks, I estimate equation (8) using the BP estimator in equation (6) for each country return series that rejects the hypothesis of no breaks. Figure 4 plots the break-point estimates for each year by country along with its confidence intervals for the $5 \%$ marginal significance case. As the figure shows, except for a few notable exceptions, the confidence intervals around the breaks are contained within two to three years. ${ }^{23}$

Panel $\mathrm{C}$ of Table 3 shows the effects on the parameter $\beta_{\varsigma}^{\ell}$ across time intervals. For illustrative purposes, I average the estimates into portfolios across country returns using Market Weights and Equal Weights. For each portfolio, I sort $\beta_{\varsigma}^{\ell}$ into bins in which parameters are stable at the $5 \%$ MSL. ${ }^{24}$ For example, the column labeled "Period 1" corresponds to country level statistics over the intervals when $\beta^{\ell}=\beta_{1}^{\ell}$, "Period $2^{\prime}$ corresponds to $\beta^{\ell}=\beta_{2}^{\ell}$, and so forth through "Period 4." Note that the time intervals corresponding to these estimates differ across countries and therefore do not generally incorporate common points in time, an implication I amend in Section 4. For countries that do not show instability, parameters are reported under "Period 1" throughout the sample, implying more observations in that bin. "Period 4" has only two observations, since only Canada and Chile demonstrate any evidence of three breaks. The table reports the cross sectional mean of the beta estimates using equation (8). The mean betas generally increase over the periods toward one. For example, the market weighted portfolio beta mean is only about 0.35 in Period 1 , but is about 0.80 for Period 2, and similarly increases for the later periods as well. Taken together, these parameters are consistent with evidence from the literature showing that international comovements are rising.

\footnotetext{
${ }^{23}$ Exceptions are the breaks in the late 1970s to early 1980s of Denmark and Ireland and the single break for Taiwan in the 2000s. For countries with more than one break, subsequent break dates are generally more tightly estimated.

${ }^{24}$ For the MSLs of $1 \%$ and $10 \%$ the estimates are virtually the same. Similar patterns also hold when portfolios are disaggregated into emerging versus developed markets and into different world regions.
} 


\subsection{Are Company Returns Explained by Country Market Changes?}

Using the evidence of breaks at the country market level, I now ask whether these changes explain the results of changes in betas previously found for cross-listed firms in Table 2. To test for this relationship, I analyze a constrained form of the model by substituting the estimates from equation (8) into equation (1). Denoting by $\widehat{\delta}$ the estimate from equation (8) for parameter $\delta$, the restricted form of equation (1) can be written:

$$
r_{t}^{i \ell}=\alpha_{q}^{i \ell}+\beta_{q}^{i \ell} \widehat{\alpha}_{\varsigma}^{\ell}+\beta_{q}^{i \ell} \widehat{\beta}_{\varsigma}^{\ell} r_{t}^{u}+\beta_{q}^{i u} r_{t}^{u}+\beta_{q}^{i \ell} \widehat{u}_{t, \varsigma}^{\ell}+e_{t}^{i \ell}, \text { for } q=1, \ldots, \mu^{i}+1
$$

where now $\mu^{i}$ is the number of breaks for cross-listed firm $i$ not explained by changes at the market level and $q$ are the time intervals during which these firm-level parameters are constant after conditioning on market-level changes.

Estimating equation (9) with the same methodology as above delivers three pieces of evidence useful to understanding potential cross-listed firm breaks. First, using the sequential sup(F) tests, I test for $\mu^{i}$, the number of breaks by firm not explained by the market changes. Second, I recover the firm-specific parameters $\left\{\widehat{\alpha}_{q}^{i \ell}, \widehat{\beta}_{q}^{i \ell}, \widehat{\beta}_{q}^{i u}\right\}$. In particular, note that when $\mu^{i}=0$ these parameter estimates simply provide the time-invariant firm parameters $\left\{\alpha^{i \ell}, \beta^{i \ell}, \beta^{i u}\right\}$. Third, given these estimates, I then test whether the recovered firm parameters indicate breaks against the home market or the US market. ${ }^{25}$

Table 4 reports summary statistics of foreign market breaks and company breaks after conditioning on the market breaks based upon estimates of equation (9) conditioned on the world market return equation (8). To get a sense of how many firms may be affects by breaks at the market

\footnotetext{
${ }^{25}$ By conditioning the estimation on the first stage country regression parameter estimates, this second stage may suffer from a generated regressions problem that will understate the true standard errors thereby potentially biasing the Wald tests toward rejection. If so, my findings may even understate the number of firms that do not reject the hypothesis, rendering my conclusions conservative.
} 
level, Panel A of the table provides a summary of the number and proportion of firms that are domiciled in countries with One Break $\left(n^{\ell}=1\right)$, Two Breaks $\left(n^{\ell}=2\right)$, and Three Breaks $\left(n^{\ell}=3\right)$. The final column labeled "All" shows the proportion of firms with home markets that reject stable parameters for $n^{\ell} \geq 1$ at about $95 \%$. Thus, most of the firms come from countries with evidence of structural instability against the US. Also $62 \%$ come from countries with one break, while only $9 \%$ of the firms come from countries that show evidence of two breaks. On the other hand, $24 \%$ of the firms come from countries with three breaks. ${ }^{26}$

Panel B of Table 4 shows the results of the test for breaks in the company stock returns after conditioning on any country breaks. In particular, the table reports the proportion of firms that reject the sequential $\sup (\mathrm{F})$ test for breaks after conditioning on the estimated market return parameters, $\widehat{\alpha}_{\varsigma}^{\ell}$ and $\widehat{\beta}_{\varsigma}^{\ell}$. Strikingly, the column labeled "No Breaks" indicates that 277 firms or about $49 \%$ of the firms do not show evidence that $\mu>0$ in equation (9). That is, there are no breaks detected after conditioning on the country level changes. For those with estimated breaks, the remaining three columns of Table 4 Panel B show that the returns from these firms appear to have only one break. In particular, data from 231 firms could not reject the hypothesis of more than one break while 55 firms appeared to have two breaks, and only 6 of the firms indicated three breaks beyond the country level.

Even though there may be estimates of breaks beyond those at the country level, the changes do not necessarily reflect changes in estimated betas at the firm level. To investigate this possibility, I conduct Wald tests that the parameters $\widehat{\delta}_{q}^{i \ell}=\delta^{i \ell}$ across subperiods. Table 4 Panel C examines the potential sources of rejecting parameter stability by the Independent Breakers. These parameter stability tests use the definition for the estimated parameters in equation (9) to identify the firm level parameters over the country subintervals. For this purpose, I recover the implied estimates

\footnotetext{
${ }^{26}$ This latter result is largely due to Canada which has the largest number of foreign companies in the US, but also has three breaks, potentially arising from its longer process of integration with the U.S., as discussed in Section 4.
} 
of company parameters within the constant country subperiods as: $\left\{\beta_{\zeta}^{i \ell}, \beta_{\zeta}^{i u}\right\}$ where $\zeta$ are the time intervals implied by the country return estimates in equation (8). I then calculate a series of Wald tests for each firm based upon the company-specific parameter estimates.

As preliminary information, the first two columns in Table 4 Panel B report the proportion and number of firm-level rejections of the hypotheses that each of the two betas are zero. If the beta on the company's home market is zero, i.e., $\beta_{\zeta}^{i \ell}=0$ for all $\zeta$, then there is no local effect on the stock return during the periods. Alternatively, when the beta on the US market is zero, $\beta_{\zeta}^{i u}=0$, the stock depends only on the home market effects. As the first two columns of Panel C show, however, most firms have significant local and US betas with shares of rejections above $50 \%$. For firms that reject constant betas after conditioning on changes at the market level, the last two columns of Panel $\mathrm{C}$ provide information about whether these rejections are due to changes in home betas, $\beta_{\zeta}^{i \ell}$, or US betas, $\beta_{\zeta}^{i u}$. As those columns show, $63.4 \%$ of the companies reject the hypothesis that home betas are constant while $44.5 \%$ reject the hypothesis that US betas are constant. Thus, an important source of breaks for these firms is the relationship with their own home market, a relationship I examine more closely in the next section.

Taken together with the number of Non-Breakers from Table 2 implies that only $28 \%$ of the firms reject both the hypothesis of no breaks and the hypothesis that these breaks can be explained at the market level. Below I call these firms "Independent Breakers."

The first column of Panel D of Table 4 summarizes information about the companies that show evidence of independent breaks, the Independent Breakers, compared to those that did not, Independent Non-Breakers. As noted earlier, Independent Breakers only account for about $28 \%$ of the firms. As found in Table 2, the incidence of breakers is quite similar for Developing versus Emerging markets as well as for NYSE versus NASDAQ listers. Also, the tendency for the Breakers to be older and have higher market cap remains. The panel also shows that over $70 \%$ of companies 
cross-list before the first break date and that on average these firms are younger at 917 weeks than the average Independent Breakers. This picture is seemingly at odds with the older average age of Independent Breakers, suggesting that this average may belie important compositional effects. To get a better picture of the typical Independent Breaker firm with breaks after cross-listing, therefore, I next analyze the cross-sectional distribution.

\subsection{What Do Firms That Have Breaks After Cross-listing Look Like?}

These results naturally raise an important question: What features are shared by the majority of Independent Breakers who experience breaks in their risk exposures against the US significantly after cross-listing? To answer this question, I estimate multinomial logit regressions for the likelihood that the cross-listing date for each of the "Independent Breaker" companies occurred within one of the three intervals: (a) before the confidence interval of the first break, labeled "Before"'; (b) within the confidence interval of all estimated breaks per firm, $m^{i}$, labeled "During"; and (c) after the confidence interval of any breaks (excluding "During"), labeled "After." The omitted case is the latter so that the coefficients reflect the odds relative to the firms with cross-listing dates "After" the estimated breaks.

The columns of Table 5 Panel A report the results for various specifications of the explanatory variables regarding the companies including the logarithms of firm age and of the average market cap over time. In all versions of the model, the "During" category variables are statistically insignificant. By contrast, the patterns for the "Before" category reveal some interesting patterns. In all cases, the constant for the "Before" category is significantly positive, reflecting the fact that a sizeable majority of firms have a cross-listing date that precedes the confidence interval of any breaks. In addition, "Age" is significantly negative, indicating that younger firms are significantly more likely to cross-list before any breaks. This finding is consistent with the view that smaller, less visible 
companies are likely to have structural changes after cross-listing in the U.S. Moreover, the negative coefficient on Market Cap Mean indicates that the likelihood of cross-listing before any breaks is generally negatively related to market value, although not significantly so.

If U.S. investors learn about some firms after cross-listing, it may also be because these firms come from countries with less stringent government regulation. To examine this possibility, I ask whether the tendency to have a break after cross-listing is related to accounting and regulatory standards from their home country. For this purpose, I consider two different data sets. The first data set is from Bushman, Piotroski, and Smith (2004) who examine an indirect private information acquisition measure of pooled investor activity. ${ }^{27}$ Following Ammer, Holland, Smith and Warnock (2012), I form dummies that equal one if the countries are above the median. Column 2 labeled "Pooled Investors" in Table 5A reports the results for this measure. The coefficient for this characteristic is significantly negative at -0.868 implying that companies from home countries with lower information acquisition are more likely to have changes in their betas after the cross-listing date, rather than during the confidence interval around the cross-listing event.

As the second data set, I also consider the Governance Quality Measure from the Worldwide Governance Indicators published by the World Bank through 2015. For this purpose, I again create a dummy equal to one if the measure is above median. The negative coefficient reported in Column 3 labeled "Home Regulations" of Table 5 Panel A shows that low home governance quality is significantly related to firms that break after cross-listing. This result implies that companies with home markets that have lower governance requirements are more likely to have breaks after cross-listing, suggesting U.S. investors learn about these companies over time.

Another reason why Independent Breakers may have significant breaks after cross-listing is that they previously had low sales in foreign markets, and are therefore less visible as a company outside

\footnotetext{
${ }^{27}$ This measure is from Beck, Demirguc-Kunt, and Levine (1999). They also examine a different measure based upon inside information, but with more limited data observations.
} 
of their home market. Following Cai and Warnock (2012) who use Worldscope data to analyze the trade content of companies, I match the data from Datastream for my companies with the data on foreign sales as a share of total sales. One difficulty with these data is that there are missing values for some companies while others have extreme values indicating data entry errors. Once these companies are dropped from the sample, only 31 Independent Breaker companies remain in the sample that break after cross-listing. Nevertheless, Column 4 of Table 5 Panel A labeled "Foreign/Total Sales" shows that indeed companies with breaks after cross-listing tend to have lower foreign sales. However, perhaps due to the limited number of companies, that relationship is not significant.

Likely candidates for these types of firms are those coming from emerging markets. To consider this possibility, Column 1 of Table 5, Panel B studies companies from emerging markets relative to others. The estimates show that companies from emerging markets are less likely to crosslist before the break and more likely to cross-list during the break with negative and positive coefficients, respectively. However, in neither case are the coefficients statistically significant. This result may be driven by the large number of companies from North America. To investigate the role of these companies, Column 2 of Table 5, Panel B shows that firms domiciled in North America are significantly more likely to cross-list before any structural breaks, even after controlling for age and market value. To understand whether this finding is driven by Canada or Mexico, Column 3 of Panel B repeats this analysis but drops Mexican firms. As the first two columns report, the coefficients are very similar to the overall North American results.

Why then are North American companies more likely to cross-list before any estimated structural changes? The answer appears to lie in the longer history of integration between these markets and the US, thereby generating the preponderance of North American stocks on US exchanges. For example, as Figure 4 shows, the history of integration generates three estimated break dates be- 
tween Canada and the U.S., the first one as early as the 1970s. The length of time period implied by these three Canadian market-U.S. market breaks make it more probable that changes in Canadian company asset pricing relationships materialize during these periods. Similarly, while the estimated break between the US and Mexico occurred relatively late, at around 2004, this period coincided with several commercial and financial deregulation policies as well as increased privatization. During this period, many Mexican companies that were cross-listed also began to co-move more closely with the US market. As a result, it is likely that the country-level break coincided with more firm-level breaks.

If this conjecture is valid, then the probability of having a break that is different than the country-level break should be significantly lower for North American firms compared to the other countries. The last columns of Table 5 Panel B verify this conjecture. The columns labeled "Independent Breakers" report the results of a logit regression in which the dependent variables is a dummy equal to one if the firm-break date is statistically significantly different from the countrybreak date. As the table shows, the coefficient for "North America" is significantly negative indicating that firms from these countries are less likely to be Independent Breakers. ${ }^{28}$ Decompositions of these regressions into Canada versus Mexico show that the estimate is uniformly negative although not always significantly so. Overall, then, while most North American firms experience structural changes as part of a larger market integration, the openness between North American market has historically allowed more cross-listing, leading to a correspondingly higher number of firms from these countries to cross-list before any breaks.

\footnotetext{
${ }^{28}$ By contrast, similar analysis for firms from other continents and subgroups show no significant pattern.
} 


\section{Do Breaks Coincide with Market Integration?}

The analysis so far has analyzed the timing of changes in the relationship between market-level and firm-level changes in risk exposures to the US market. In this section, I ask whether the timing and evolution of betas is consistent with existing findings. I also evaluate the robustness of breaks to gradual integration and consider their economic significance on investors.

\subsection{Are the Implied Risk Exposures Consistent with Market Integration?}

Although the market integration studies vary in their approaches, a common finding is that global betas and correlations have tended to increase towards one. ${ }^{29}$ To address whether my estimates are consistent with these results, I follow two basic steps. First, as a purely descriptive measure, I ask whether the patterns of estimated parameters indicate greater sensitivity between foreign returns and the US market as found by others. For this purpose, I sort the estimated company and country returns parameters, $\beta^{i \ell}, \beta^{i u}$, and $\beta^{\ell}$, into time periods of estimated stable interval bins. As previously categorized in the intervals before and after cross-listing and reported in Table 2, Panel C, I calculate the Equally-Weighted and Market-Weighted portfolio means of the $\beta^{i \ell}$ and $\beta^{i u}$ estimates. As shown there, these means have the same tendency for the estimates of the U.S. market betas to increase, but demonstrate more mixed estimates for the home market betas, consistent with the literature (not shown for parsimony.)

As a second step to check whether my estimates are consistent with the literature, I study the evolution of the sensitivity of a portfolio of these assets over time. I further evaluate whether these parameter estimates reflect standard trends by calculating implied portfolio sensitivities over calendar time. For this purpose, country and company estimates are sorted by year to form annual market-weighted portfolio parameters of foreign markets and of cross-listed firms, respectively.

\footnotetext{
${ }^{29}$ While I will generally continue to refer to this tendency as "market integration," Section 1 noted that increasing correlations and betas toward one need not necessarily correspond to market integration.
} 
Figure 5a plots the parameter estimates over time. Despite some variation, the portfolio beta on the local market $\beta^{i \ell}$ hovers around 0.7 and is relatively unchanged. However, there is an increase over time in both the betas of the country returns and the foreign companies on the US, $\beta^{\ell}$ and $\beta^{i u}$, respectively. This increase is betas against the US suggests a decrease in international diversification potential, as has been found in the literature.

Notably, Figure 5a shows that the US portfolio sensitivities for other markets, $\beta^{\ell}$, and for the cross-listed stocks, $\beta^{i u}$, appear to track very closely together. This behavior suggests that crosslisted firms may drive the increase in betas of their home markets against the US. To disentangle these effects, I decompose the portfolio of foreign firms into those that are cross-listed and those that are not. As depicted in Figure 5b, the betas against the US increase for both groups, suggesting market integration for non-cross-listers as well as cross-listers. However, throughout the entire sample, the betas of non-cross-listers are always below cross-listers, indicating that cross-listers are more responsive to US market movements.

\subsection{Do Emerging Market Break Dates Correspond with Liberalization?}

The literature described in Section 1 noted that while markets have generally become more integrated, emerging markets remain partially segmented. Moreover, papers such as Bekaert and Harvey (2000) and Bekaert, Harvey, and Lumsdaine (2002), hereafter BHL, relate variables such as cross-listed stocks to the liberalization dates of these emerging markets. Therefore, it is useful to compare the country break estimates to the BHL dates, and the official liberalization dates. Table 6 reports the break date estimates for the emerging markets in my sample along with those countries in common with BHL. Since the sample period for BHL ends in 1995, for some countries our samples only overlap for a short window. To potentially allow a finer detection of breaks, therefore, I reduce the trimming constraint $\varepsilon$ for the Bai-Perron estimator to $5 \%$ relative to the constraint 
of $15 \%$ used in the above analysis. The first two columns of Table 6 report the estimated breaks for the two constraints on $\varepsilon$. With the exception of Taiwan, the estimates are very similar, if not identical, across constraints. ${ }^{30}$

Column 3 gives the start date for each country, while the fourth column notes the number of years of overlap with BHL. The fifth column lists the estimated dates from BHL. Given the earlier sample, the estimated dates are generally earlier than the estimates in Columns 1 and 2, particularly for those with very little overlapping samples. However, my estimates and those in BHL have distinct similarities for Chile, Taiwan, and Venezuela.

Column 6 of Table 6 provides the official liberalization dates as reported by Bekaert and Harvey (2000). BHL find that their estimated break dates tend to be later than the official liberalization dates, arguing that the market integration process may take time following the liberalization. That pattern becomes even more pronounced in my later sample periods. These breaks may be due to gradual market integration over time, as argued by BHL, and analyzed in the next subsection.

\subsection{The Effects of Gradual Parameter Shifts}

The discussion above describes shifts in the parameters arising from discrete and abrupt shifts in the parameters, following the approach of the cross-listing literature that focuses upon the crosslisting event as a point in time. Moreover, the liberalization literature has often looked at changes around events surrounding economies opening up. On the other hand, it seems likely that at least some of the changes have taken place more gradually.

In the context of understanding more gradual underlying parameter changes, Bai and Perron (2003a) show that the estimated fractions of time intervals implied by equation (6) hold under very general circumstances. Moreover, they note that allowing for lags of the dependent variable, as

\footnotetext{
${ }^{30}$ As noted in Figure 4, the confidence interval for Taiwan with the trimming constraint of $15 \%$ was quite wide, encompassing several years. With a tighter constraint, the model estimates two breaks, one at May 1990 and the other at September 2001.
} 
in the case of an autoregressive model, allows for persistent changes in parameters for the period following the break. As such, the changes take effect gradually. Therefore, to determine how much the break dates found above would be affected if they were presumed to be driven by a more gradual and dynamic process, I estimate an alternative auto-regressive form of the world CAPM equation (2). Specifically, I assume that the residuals to the world return model have the form: $u_{t}^{\ell}=\rho_{\tau}^{\ell} r_{t}^{\ell}+\widetilde{u}_{t}^{\ell}$, where now $\widetilde{u}_{t}^{\ell}$ is i.i.d.

Figure 6 depicts the estimated break dates at the $5 \%$ marginal significance level for the countries. The error bands indicate the $90 \%$ confidence intervals around these gradual break estimates. The figure also plots the breaks for the abrupt break model from Figure 1 for comparison. ${ }^{31}$ For a few of the countries, the standard errors of the breaks are wider than the abrupt break model, most notably Finland. However, two main features can be seen. First, almost all of the breaks with the abrupt break model occur within the confidence interval of the gradual break model. Second, the few exceptions when estimated abrupt breaks occur significantly outside of the error bands, these breaks all materialize early in the sample. For example, the two early breaks for Canada and the first break for Denmark and Ireland are before those implied by the gradual break. As such, the gradual break analysis may pick up changes that have accumulated over some period, consistent with the interpretation in Bai and Perron (2003a).

Overall, this analysis suggests that the break date analysis above is relatively robust to an interpretation that the breaks occur more gradually, given the preponderance of later break estimates.

\subsection{Economic Significance}

Above, I showed the empirical significance in the pattern of shifting betas of cross-listed firms, but not the economic significance. Although a full structural model is beyond the scope of this paper,

\footnotetext{
${ }^{31}$ For clarity, countries without evidence of at least one gradual and one abrupt break are ommitted. No countries showed evidence of three gradual breaks.
} 
one clear economic impact from changes in beta sensitivities can be felt by U.S. investors who hold these stocks. For example, Errunza, Hogan, and Hung (1999) show that U.S. investors may diversify foreign equity risk without going abroad by holding domestically-traded securities that have foreign exposure. An important component of the foreign risk portfolio spanning ability of these securities comes from cross-listed equities. However, the evidence above finds that the betas of foreign securities have been increasing over time against the U.S. market, suggesting that this ability to diversify may have declined. Hence one area to assess the economic significance in the changing risk exposures is in the decline in risk-reduction potential. ${ }^{32}$

As one way to answer this question, I consider the potential impact on portfolio volatility to US investors who are seeking to diversify using cross-listed stocks. For this purpose, I evaluate a straightforward thought experiment. A variance-minimizing US investor can hold two assets: the U.S. market portfolio and a portfolio of cross-listed foreign companies constructed using the estimates of betas and residual variances found in the analysis above. Based upon these two portfolios, the investor decides each year how much to hold of the foreign cross-listed portfolio and the U.S. market in order to minimize portfolio variance. Using these portfolio allocations, then, I calculate the equity portfolio variability that is reduced when diversifying using cross-listed stocks.

In order to form the set of companies to include in the cross-listed firm portfolio, I must make an assumption about when U.S. investors can hold these foreign companies. For this purpose, I analyze the variance minimization under two extreme assumptions. In one, I assume that U.S. investors can hold the foreign stocks as soon as they are listed in their home markets. In the other extreme, these foreign stocks are investable only once they are listed in the U.S. market. Clearly, reality lies somewhere in between.

Table 7 reports the results of this analysis. The rows labeled "Decline in Portfolio StDev in

\footnotetext{
${ }^{32}$ As described in Section 1, the market integration literature has generally found that the ability to diversify risks internationally has declined. Therefore, my goal here is more specific: to put some economic content to the estimates in the cross-listed stocks by asking how the changes found above would impact a U.S. investor.
} 
\%" and "Decline as \% of U.S. Market StDev" give the decline in the annual portfolio standard deviation and this decline as a percentage of U.S. market standard deviation, respectively, both reported as annual averages over decades. The optimal portfolio share in the foreign stocks is given in the last row. The table provides the averages of these numbers by decade assuming a "Short Sale Constraint" for the four decades as listed in the first four columns. However, these constraints are only binding in the 2000s. For this reason, the final row also shows the effects in the absence of the "Short Sale Constraint."

Table 7 Panel A reports these statistics under the assumption that foreign firms are investable upon home-listing. Notably, the first four columns show that the percentage of portfolio standard deviation as a share of the U.S. market declines from $19.6 \%$ in the 1970 s to $0.1 \%$ in the 2000 s when short sale constraints are imposed. The final column shows that, if short sales constraints were not in place, the high betas between the U.S. market and the cross-listed firms would make variance-minimizing U.S. investors prefer to short the foreign stocks in the amount of $65 \%$ of their portfolio.

Panel B of Table 7 gives a similar picture under the alternative assumption that foreign firms are investable upon listing in the U.S. market. The proportion of U.S. market volatility that can be diversified with the cross-listed stocks declines from $8.72 \%$ in the 1970 s to zero in the 2000s. However, the amount that can be diversified is generally smaller than under Panel A. The reason for this finding is clear. Foreign stocks generally have higher betas against the U.S. market once they become cross-listed. Therefore, if U.S. investors can only hold these stocks once they are cross-listed, then the diversification properties of these foreign stocks will be lower.

Finally, Panel C of Table 7 considers how a finer partition of the trimming parameter maintained throughout most of the analysis would affect these results. In this case, I continue to assume that foreign stocks become investable only after cross-listing in the U.S., but assume that $\varepsilon=5 \%$ instead 
of $\varepsilon=15 \%$. The panel shows results similar to Panel $\mathrm{B}$, albeit with generally lower diversification potential outside of the 1970s. Intuitively, the greater variability in betas generated by a finer trimming parameter appears to create increased portfolio variability on its own.

Despite this wide range of assumptions about foreign company investability, this analysis shows that the impact of the changing betas of cross-listed stocks has a significant economic impact upon investors. The betas of these foreign stocks would have provided substantial diversification benefits in the 1970 s by reducing the volatility of a U.S. investor's portfolio between $9 \%$ to $20 \%$. However, that diversification benefit effectively disappears in the 2000 s.

\section{Conclusion}

The changing risk exposures of firms to market indices after cross-listing is often cited as evidence for market segmentation. Also, equity markets appear to have become more integrated over time, especially for developed economies. Based upon evidence for these findings from two strands of literature, this paper asks whether changes in the risk exposures of cross-listed firms can be explained by changes at the market-level.

For this purpose, I test for and estimate potential breaks in the relationship assumed in the cross-listing literature between firm and market returns. Consistent with that literature, I find statistically significant evidence for breaks for a majority of the firms. However, when I condition those breaks on similar changes at the market level, I find a surprising result. For a majority of over $70 \%$ of the firms, I cannot reject the hypothesis that there is no break beyond those at the market level. This result suggests that perceived changes in the risk exposures for many cross-listed firms may derive from a more general market integration, a trend shown to be consistent with the estimates. Moreover, firms that continue to have breaks after conditioning on the market changes are more likely to have breaks after cross-listing. This tendency is pronounced for younger firms, 
and those from home countries with less stringent governmental restrictions, possibly due to the longer time required for investors to learn about them.

Overall, the evidence in this paper suggests that the presumption in the cross-listing literature that home and foreign market returns can be used to condition the cost of capital estimates may need to be reconsidered. The evidence is only for a group of foreign companies in the U.S. market so the generality of these findings remain to be seen. However, for this set of companies, the evidence clearly indicates that changes in firm-level risk exposures may derive from changes in their home market relative to the host market. Moreover, for firms that do have changes in risk exposures independent of their home markets, these changes occur after cross-listing, putting into question the standard notion that the changes coincide with the cross-listing event itself. As such, the evidence of lowering cost of capital may derive from a general integration of markets. This paper highlights the importance of understanding the sources of these interactions. 


\section{REFERENCES}

Ammer, John; Holland, Sara B; Smith, David C; Warnock, Francis E. "U.S. International Equity Investment," Journal of Accounting Research, 50.5 Dec 2012: 1109-1139.

Andrews, Donald W K, "Heteroskedasticity and Autocorrelation Consistent Covariance Matrix Estimation," Econometrica, 59:3, May 1991, 817-58.

Andrews, Donald W.K., "Tests for parameter instability and structural change with unknown change point," Econometrica 61,1993, 821-856.

Bai, Jushan; Perron, Pierre, "Estimating and Testing Linear Models with Multiple Structural Changes," Econometrica, 66:1, January 1998, 47-78.

Bai, Jushan; Perron, Pierre, "Computation and Analysis of Multiple Structural Change Models," Journal of Applied Econometrics, 18:1, Jan.-Feb. 2003a, 1-22.

Bai, Jushan; Perron, Pierre, "Critical Values for Multiple Structural Change Tests," Econometrics Journal, 6:1, 2003b, pp. 72-78.

Baruch, Shmuel; Karolyi, G Andrew; Lemmon, Michael L., "Multimarket Trading and Liquidity: Theory and Evidence," Journal of Finance, 62.5, Oct 2007, 2169-2200.

Beck, Thorsten; Demirguc-Kunt, Asli; Levine, Ross. "A New Database on Financial Development and Structure," World Bank Economic Review 14 (1999): 597-605.

Bekaert, Geert; Harvey, Campbell R., "Time-Varying World Market Integration," Journal of Finance, 50.2, Jun 1995, 403-444.

Bekaert, Geert; Harvey, Campbell R, "Foreign Speculators and Emerging Equity Markets," Journal of Finance, 55:2, April 2000, 565-613. 
Bekaert, Geert; Harvey, Campbell R; Lundblad, Christian T; Siegel, Stephan. "What Segments Equity Markets?" Review of Financial Studies, 24.12, Dec 2011, 3841-3890.

Bekaert, Geert; Harvey, Campbell R; Lumsdaine, Robin L., "Dating the Integration of World Equity Markets," Journal of Financial Economics, 65:2, August 2002, 203-47.

Bekaert, G; Hodrick, R., Zhang, L., "International Stock Return Comovements," Journal of Finance, 64:6, December 2009, 2591-2626.

Bonser-Neal, C.; Brauer, G.; Neal, R.; Wheatley, S.; "International Investment Restrictions and Closed-End Country Fund Prices," Journal of Finance, 45:2, June 1990, 523-47.

Bushman, Robert M; Piotroski, Joseph D; Smith, Abbie J. "What Determines Corporate Transparency?" Journal of Accounting Research, 42, 2004, 207-252.

Cai, Fang; Warnock, Francis E. "Foreign Exposure through Domestic Equities," Finance Research Letters, 9, 2012, 8-20.

Carrieri, F.; Chaieb, I.; Errunza, V. "Do Implicit Barriers Matter for Globalization?" Review of Financial Studies, 26:7, 2013,1694-1739

Carrieri, F.; Errunza, V.; Hogan, K. "Characterizing World Market Integration Overtime", Journal of Financial and Quantitative Analysis, 42, 2007, 915-940.

Christoffersen, Peter; Errunza, Vihang; Jacobs, Kris; Langlois, Hugues; "Is the Potential for International Diversification Disappearing?" Review of Financial Studies, 25, 2012, 3711-3751.

Coffee, J. "Racing towards the top? The impact of cross-listings and stock market competition on international corporate governance," Columbia Law Review 102, 2002,1757-1831.

Coeurdacier, Nicolas; Rey, Helene. "Home Bias in Open Economy Financial Macroeconomics," Journal of Economic Literature, 51.1 2013: 63-115. 
Doidge, C., Karolyi, G. A., Stulz, R. M. "Why are foreign firms that are listed in the U.S. worth more?" Journal of Financial Economics 71, 2004, 205-238.

Dumas, B.; Harvey, Campbell R; Ruis, P; "Are Correlations in International Stock Returns Justified by Subsequent Changes in National Outputs?" The Journal of International Money and Finance, 22 (2003), 777-811.

Dumas, B.; Solnik, B., "The World Price of Foreign Exchange Risk," Journal of Finance, 50:2, June 1995, 445-79.

Errunza, Vihang; Hogan, Ked; Hung, Mao-Wei. "Can the Gains from International Diversification Be Achieved without Trading Abroad?" Journal of Finance, 54.6 1999: 2075-2107.

Errunza, V.; Losq, E.; "International Asset Pricing under Mild Segmentation: Theory and Test," Journal of Finance, 40.1, Mar 1985, 105-124.

Errunza, V.; Miller, D.P.; "Market Segmentation and the Cost of Capital in International Equity Markets," The Journal of Financial and Quantitative Analysis 35, 2000, 577-600.

Errunza, V.; Senbet, L.W.; and Hogan, K.; "The Pricing of Country Funds from Emerging Markets: Theory and Evidence," International Journal of Theoretical and Applied Finance 1, 1998, 111-143.

Foerster, S.; Karolyi, G. A.; "The Effects of Market Segmentation and Investor Recognition on Asset Prices: Evidence from Foreign Stocks Listing in the U.S.," Journal of Finance 54, 1999, 981-1014.

Hail, L., Leuz, C.; "Cost of Capital Effects and Changes in Growth Expectations around U.S. Cross Listings," Journal of Financial Economics 93, 2009, 428-454.

Hansen, B.; "Sample splitting and threshold estimation," Econometrica, 2000, 68, 575-603. 
Henry, P.B.; "Stock Market Liberalization, Economic Reform, and Emerging Market Equity Prices," Journal of Finance, 55:2, April 2000, 529-64.

Karolyi, G Andrew; "Why Do Companies List Shares Abroad? A Survey of the Evidence and its Managerial Implications," Financial Markets, Institutions and Instrument 7, 1998, 1-60.

Karolyi, G A., "The World of Cross-Listings and Cross-Listings of the World: Challenging Conventional Wisdom," Review of Finance, 10:1, 2006, 99-152.

Karolyi, G. A.; Wu, Y.; "The Role of Investability Restrictions on Size, Value, and Momentum in International Stock Returns," Johnson School University of Cornell Working Paper, 2012

Kim, E. H.; Singal, V. "Stock market opening: Experience of emerging economies," Journal of Business 73, 2000, 25-66.

Lewis, K. K. "Global Asset Pricing," Annual Review of Financial Economics, 3, 2011, 435 466.

Lewis, K.K.; Liu, E.X.; "Evaluating International Consumption Risk Sharing Gains: An Asset Return View," Journal of Monetary Economics, 71, 2015, 84 - 98.

Miller, D. P. "The market reaction to international cross-listing: Evidence from depositary receipts, Journal of Financial Economics 51, 1999, 103-123.

Pagano, M.; Roell, A. A.; Zechner, J. "The geography of equity listing:Why do companies list abroad?" Journal of Finance 57, 2002, 2651-2694.

Pukthuanthong, K.; Roll, R., "Global Market Integration: An Alternative Measure and Its Application," Journal of Financial Economics 94,2, 2009, 214-232.

Sarkissian, S.; Schill, M.J. "The Overseas Listing Decision: New Evidence of Proximity Preference" Review of Financial Studies, 17:3 2004, 769-809. 
Sarkissian, S.; Schill, M.J. "Are There Permanent Valuation Gains to Overseas Listing?" Review of Financial Studies, 22:1 Jan 2009, 371-412

Sarkissian, S.; Schill, M.J. "Cross-Listing Waves" Journal of Financial and Quantitative Analysis, forthcoming.

Stulz, R. M. "Globalization, corporate finance, and the cost of capital," Journal of Applied Corporate Finance 12, 1999, 8-25.

White, H. "Heteroskedasticity-Consistent Covariance Matrix Estimator and a Direct Test for Heteroskedasticity," Econometrica, 48:4, May 1980, 817-38. 
Table 1: Summary Statistics for Foreign Companies

\section{Listed in US Exchanges}

\begin{tabular}{|c|c|c|c|c|}
\hline \multirow[t]{2}{*}{ Stock Exchange } & Market Begin & No. of & No. of & Average Firm \\
\hline & Data & Firms & Countries & Observations \\
\hline NYSE & Jan 2, 1970 & 380 & 39 & 1092 \\
\hline NASDAQ & Feb 8, 1971 & 196 & 28 & 862 \\
\hline Both Exchanges & - & 576 & 42 & 977 \\
\hline \multicolumn{5}{|c|}{ Panel B: Summary Information about Foreign Firms Listed by Country } \\
\hline Country & $\begin{array}{c}\text { Market Begin } \\
\text { Data }\end{array}$ & $\begin{array}{c}\text { No. of Firms- } \\
\text { NYSE }\end{array}$ & $\begin{array}{c}\text { No. of Firms } \\
\text { NASDAQ }\end{array}$ & $\begin{array}{c}\text { Average Firm } \\
\text { Observations }\end{array}$ \\
\hline Argentina & Aug 6, 1993 & 9 & 3 & 733 \\
\hline Australia & Jan 5, 1973 & 12 & 8 & 1324 \\
\hline Austria & Jan 5,1973 & 2 & 0 & 466 \\
\hline Belgium & Jan 5, 1973 & 1 & 0 & 1917 \\
\hline Brazil & Jul 8, 1994 & 35 & 1 & 676 \\
\hline Canada & Jan 5,1973 & 57 & 63 & 1009 \\
\hline Chile & Jul 7, 1989 & 17 & 0 & 457 \\
\hline China & Jul 30, 1993 & 12 & 5 & 527 \\
\hline Colombia & Mar 13, 1992 & 1 & 0 & 764 \\
\hline Denmark & Jan 5, 1973 & 2 & 2 & 1401 \\
\hline Finland & Mar 25, 1988 & 4 & 0 & 1055 \\
\hline France & Jan 5, 1973 & 22 & 10 & 921 \\
\hline Germany & Jan 5, 1973 & 15 & 3 & 869 \\
\hline Greece & Jan 5, 1990 & 3 & 1 & 760 \\
\hline Hong Kong & Jan 5, 1973 & 7 & 5 & 579 \\
\hline Hungary & Jun 21, 1991 & 1 & 0 & 620 \\
\hline India & Jan 5, 1990 & 8 & 3 & 772 \\
\hline
\end{tabular}


Table 1: Summary Statistics for Foreign Companies

Listed in US Exchanges (cont.)

\begin{tabular}{|c|c|c|c|c|}
\hline Country & $\begin{array}{c}\text { Market Index } \\
\text { Begin Date }\end{array}$ & $\begin{array}{c}\text { No.of Firms: } \\
\text { NYSE }\end{array}$ & $\begin{array}{c}\text { No. of Firms: } \\
\text { NASDAQ }\end{array}$ & $\begin{array}{c}\text { Average Firm } \\
\text { Observations }\end{array}$ \\
\hline Indonesia & Jan 5, 1990 & 2 & 0 & 376 \\
\hline Ireland & Jan 5, 1973 & 3 & 8 & 1348 \\
\hline Israel & Jan 1, 1993 & 2 & 6 & 671 \\
\hline Italy & Jan 5, 1973 & 10 & 0 & 908 \\
\hline Japan & Jan 5,1973 & 18 & 12 & 1585 \\
\hline Korea & Sep 11, 1987 & 5 & 3 & 708 \\
\hline Luxemburg & Jan 3, 1992 & 2 & 1 & 644 \\
\hline Malaysia & Jan 3,1986 & 0 & 1 & 729 \\
\hline Mexico & May 12,1989 & 24 & 2 & 796 \\
\hline Netherland & Jan 5, 1973 & 16 & 7 & 1182 \\
\hline New Zealand & Jan 8,1988 & 1 & 0 & 475 \\
\hline Norway & Jan 4,1980 & 4 & 3 & 794 \\
\hline Peru & Jan 7, 1994 & 2 & 0 & 947 \\
\hline Philippines & Sep 11, 1987 & 2 & 1 & 411 \\
\hline Portugal & Jan 5, 1990 & 3 & 0 & 841 \\
\hline Russia & Jun 24, 1994 & 3 & 0 & 641 \\
\hline Singapore & Jan 5,1973 & 0 & 2 & 511 \\
\hline South Africa & Jan 5,1973 & 6 & 5 & 1149 \\
\hline Spain & Mar 6, 1987 & 6 & 1 & 773 \\
\hline Sweden & Jan 8, 1982 & 0 & 7 & 989 \\
\hline Switzerland & Jan 5, 1973 & 10 & 2 & 948 \\
\hline Taiwan & May 6, 1988 & 5 & 2 & 793 \\
\hline Turkey & Jan 8, 1988 & 1 & 0 & 483 \\
\hline United Kingdom & Jan 2, 1970 & 46 & 29 & 1160 \\
\hline Venezuela & Jan 5, 1990 & 1 & 0 & 671 \\
\hline
\end{tabular}




\section{Table 2 Firm Break Tests}

Panel A reports the proportion of foreign company returns rejecting the hypothesis that there are less than one, two, three and unknown breaks in the regression: $r_{t}^{i \ell}=\alpha^{i \ell}+\beta^{i \ell} r_{t}^{\ell}+\beta^{i u} r_{t}^{u}+e_{t}^{i \ell}$, where $r_{t}^{i \ell}, r_{t}^{\ell}$, and $r_{t}^{u}$ are the excess equity returns of firm $i$, country $\ell$, and the US, respectively. Panel B gives the results of the sequential $\operatorname{Sup}(\mathrm{F}) \operatorname{test}$. Panel $\mathrm{C}$ gives the number and share of companies rejecting the hypothesis of no breaks during subsamples. Panel D reports shares, age, and market cap means for firms categorized by cross-listing date relative to break dates.

\begin{tabular}{|c|c|c|c|c|c|c|}
\hline \multicolumn{7}{|c|}{ Panel A: Proportion of Companies Rejecting No Breaks } \\
\hline $\begin{array}{l}\text { Marginal Significance } \\
\text { Level }\end{array}$ & \multicolumn{3}{|c|}{$\begin{array}{l}\text { Sup F test of No Break } \\
\text { vs: }\end{array}$} & \multicolumn{3}{|c|}{$\begin{array}{l}\text { Tests of No Break vs } \\
\text { Unknown Number of Breaks }\end{array}$} \\
\hline & $\mathrm{m}=1$ & $\mathrm{~m}=2$ & $\mathrm{~m}=3$ & UD & Max & WD Max \\
\hline $5 \%$ & 0.771 & 0.799 & 0.802 & & 07 & 0.806 \\
\hline $1 \%$ & 0.676 & 0.734 & 0.715 & & 09 & 0.736 \\
\hline \multicolumn{7}{|c|}{ Panel B: Distribution of Breaks by Number } \\
\hline $\begin{array}{l}\text { Stock } \\
\text { Return } \\
\text { Set }\end{array}$ & \multicolumn{2}{|c|}{$\begin{array}{l}\text { Proportion of } \\
\text { Total Companies } \\
\text { Rejecting }\end{array}$} & \multicolumn{4}{|c|}{ Proportional \# of Breaks ${ }^{b}$ over } \\
\hline Cross-listed Firms & $\begin{array}{r}\text { Ho: No Breaks } \\
0.7 \\
0.16\end{array}$ & & 0.5 & & 0.347 & 0.107 \\
\hline \multicolumn{7}{|c|}{ Panel C: Distribution of Breaks by Subsample } \\
\hline Portfolio & $\beta^{\text {iu,Before }}$ & $\begin{array}{c}\beta^{\text {iu,After }} \\
-\beta^{\text {iu,Before }}\end{array}$ & $\begin{array}{c}\beta^{\text {iu,During }} \\
-\beta^{\text {iu,Before }}\end{array}$ & $\beta^{\text {il,Before }}$ & $\begin{array}{c}\beta^{i \ell, \text { After }} \\
-\beta^{i \ell, \text { Before }}\end{array}$ & $\begin{array}{c}\beta^{i \ell, \text { During }} \\
-\beta^{i \ell, \text { Before }}\end{array}$ \\
\hline Equally Weighted & 0.639 & 0.328 & 0.161 & 0.696 & -0.005 & 0.028 \\
\hline Market Weighted & 0.486 & 0.484 & 0.255 & 0.647 & 0.111 & 0.120 \\
\hline \multicolumn{7}{|c|}{ Panel D: Relationship to Cross-Listing Dates } \\
\hline & $\begin{array}{c}\text { Breakers/ } \\
\text { Non-Breakers }\end{array}$ & \multicolumn{5}{|c|}{ Crosslisting Date is: } \\
\hline Total Share ${ }^{c}$ & $0.772 / 0.228$ & 0.660 & 0.091 & 0.166 & 0.032 & 0.045 \\
\hline Developed Share ${ }^{c}$ & $0.762 / 0.238$ & 0.488 & 0.074 & 0.118 & 0.033 & 0.041 \\
\hline Emerging Share $^{c}$ & $0.794 / 0.206$ & 0.556 & 0.061 & 0.150 & 0.006 & 0.022 \\
\hline NYSE Share ${ }^{c}$ & $0.831 / 0.169$ & 0.646 & 0.089 & 0.172 & 0.038 & 0.048 \\
\hline NASDAQ Share ${ }^{c}$ & $0.658 / 0.342$ & 0.693 & 0.094 & 0.150 & 0.016 & 0.039 \\
\hline Age $(\text { weeks })^{d}$ & $1,063 / 768$ & 886 & 1,210 & 1,406 & 1,417 & 1,719 \\
\hline 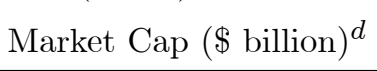 & $8,285 / 5,065$ & 7,949 & 7,413 & 9,148 & 11,786 & 9,418 \\
\hline
\end{tabular}

${ }^{a}$ Ratio of the number of companies that reject the hypothesis of no structural break over the total number of firms.

${ }^{b}$ Ratio of the number of companies that reject the sequential test of a given number of breaks plus one over the total number of Breaker companies. ${ }^{c}$ Under Breakers/Non-Breakers, the ratio of firms that reject/ don't reject the hypothesis of no breaks over the number of firms by group. Remaining columns report the ratio of the number of firms with cross-listing dates in a given time category over the number of firms rejecting the hypothesis of no break. ${ }^{d}$ Average 


\section{Table 3 Country Break Tests}

Panel A reports the proportion of foreign country returns rejecting the hypothesis that there are less than one, two, three and unknown breaks in the regression:

$r_{t}^{\ell}=\alpha^{\ell}+\beta^{\ell} r_{t}^{u}+u_{t}^{\ell}$, where $r_{t}^{\ell}$ is the excess equity return of country $\ell, r_{t}^{u}$ is the excess return of the US. Panel B gives the results of the sequential Sup(F) test. Panel C reports the weighted average of country beta estimates over constant parameter intervals, $T_{i}$.

\begin{tabular}{|c|c|c|c|c|c|}
\hline \multicolumn{6}{|c|}{ Panel A: Proportion of Countries Rejecting No Breaks } \\
\hline \multirow[t]{2}{*}{$\mathrm{MSL}^{a}$} & \multicolumn{3}{|c|}{$\begin{array}{l}\text { Sup F test of No Break } \\
\text { vs: }\end{array}$} & \multicolumn{2}{|c|}{$\begin{array}{l}\text { Tests of No Break vs } \\
\text { Unknown Number }\end{array}$} \\
\hline & $\mathrm{m}=1$ & $\mathrm{~m}=2$ & $\mathrm{~m}=3$ & UD Max & WD Max \\
\hline $5 \%$ & 0.833 & 0.929 & 0.905 & 0.905 & 0.881 \\
\hline $1 \%$ & 0.810 & 0.857 & 0.833 & 0.833 & 0.833 \\
\hline \multicolumn{6}{|c|}{ Panel B: Distribution of Break Categories } \\
\hline \multirow[t]{2}{*}{$\mathrm{MSL}^{a}$} & Prop of Countries ${ }^{b}$ & Proportio & aal \# of B & aks ${ }^{c}$ over & \\
\hline & Reject No Breaks & 1 Break & 2 Breaks & 3 Breaks & \\
\hline $5 \%$ & 0.833 & 0.743 & 0.200 & 0.057 & \\
\hline $1 \%$ & 0.810 & 0.824 & 0.176 & 0.000 & \\
\hline \multicolumn{6}{|c|}{ Panel C: Portfolio-Weighted Foreign Country Beta Estimates } \\
\hline Weight & Period 1 & Period 2 & Period 3 & Period 4 & \\
\hline Market & 0.348 & 0.802 & 0.866 & 1.109 & \\
\hline Equal & 0.378 & 0.843 & 0.799 & 0.973 & \\
\hline
\end{tabular}

${ }^{a}$ Marginal significance levels for the test of no structural break and the sequential $\sup (\mathrm{F})$ test. ${ }^{b}$ Ratio of the number of countries that reject the test of no structural break over the total number of countries. ${ }^{c}$ Proportion of countries that reject sequential test of a given number of breaks plus one over the number that reject the $\sup (\mathrm{F})$ test of no structural break. 


\section{Table 4 Foreign Market Breaks and Restrictions on Foreign Firm Pricing}

Panel A reports the number and proportion of foreign stocks listed in the US domiciled in home countries with breaks as in Table 3. Panel B reports the number and proportion of the firms that reject the hypothesis that the the estimates are stable in the equations: $r_{t}^{\ell}=\alpha_{\zeta}^{\ell}+\beta_{\zeta}^{\ell} r_{t}^{u}+u_{t, \zeta}^{\ell} ; r_{t}^{i \ell}=\alpha^{i \ell}+\beta^{i \ell} \alpha_{\zeta}^{\ell}+\left(\beta^{i u}+\beta^{i \ell} \beta_{\zeta}^{\ell}\right) r_{t}^{u}+\beta^{i \ell} u_{t, \zeta}^{\ell}+e_{t}^{i \ell}$ for each firm $i$ and home country $\ell$, and interval $\zeta=1, \ldots, n^{\ell}$ where $n^{\ell}$ is the estimated number of breaks for country $\ell$. Panel $\mathrm{C}$ reports the number and proportion of firms that reject the hypothesis that the parameters are equal to zero or constant. Panel D gives the average share and characteristics for Breaker firms as well as the share with cross-listing dates before and during estimated break intervals.

\begin{tabular}{|c|c|c|c|c|}
\hline \multicolumn{5}{|c|}{ Panel A: Firms Decomposed by Country Break Category } \\
\hline Statistic & $\begin{array}{l}\text { One Break } \\
n^{\ell}=1\end{array}$ & $\begin{array}{c}\text { Two Breaks } \\
n^{\ell}=2\end{array}$ & $\begin{array}{c}\text { Three Breaks } \\
\qquad n^{\ell}=3\end{array}$ & All \\
\hline Proportion of Firms & 0.620 & 0.089 & 0.238 & 0.946 \\
\hline No of Firms & 357 & 51 & 137 & 545 \\
\hline \multicolumn{5}{|c|}{ Panel B: Distribution of Break Categories Using Sequential Test } \\
\hline \multicolumn{5}{|l|}{ Tests for Breaks } \\
\hline Beyond country level & No Breaks & One Break & Two Breaks & Three Breaks \\
\hline Proportion of Firms & 0.487 & 0.406 & 0.097 & 0.011 \\
\hline No of Firms & 277 & 231 & 55 & 6 \\
\hline \multicolumn{5}{|c|}{ Panel C: Firms Rejecting Parameter Constancy } \\
\hline Null Hypothesis & No Local Effect & No US Effect & Local Effect & World Effect \\
\hline & & & Constant & Constant \\
\hline & $H o: \beta_{\zeta}^{i \ell}=0, \forall \zeta$ & $H o: \beta_{\zeta}^{i u}=0, \forall \zeta$ & $H o: \beta_{\zeta}^{i \ell}=\beta^{i \ell}, \forall \zeta$ & $H o: \beta_{\zeta}^{i u}=\beta^{i u}, \forall \zeta$ \\
\hline Proportion of Firms ${ }^{a}$ & 0.849 & 0.579 & 0.634 & 0.445 \\
\hline No of Firms & 248 & 169 & 185 & 130 \\
\hline
\end{tabular}




\begin{tabular}{|c|c|c|c|c|c|c|c|}
\hline \multicolumn{8}{|c|}{ Table 4 Foreign Market Breaks and Restrictions on Foreign Firm Pricing (cont.) } \\
\hline \multicolumn{8}{|c|}{ Panel D: Relationship to Cross-Listing Dates (at MSL 5\%) } \\
\hline & \multirow{2}{*}{$\begin{array}{l}\text { Ind Breakers/ } \\
\text { Non-Breakers }\end{array}$} & \multicolumn{6}{|c|}{ Crosslisting Date is: } \\
\hline & & $<$ Break 1 & $=$ Break 1 & $>$ Break 1 & $=$ Break 2 & $>$ Break 2 & $\geq$ Break 3 \\
\hline Total Share ${ }^{b}$ & $0.284 / 0.716$ & 0.716 & 0.136 & 0.105 & 0.019 & 0.019 & 0.006 \\
\hline Developed Share ${ }^{b}$ & $0.284 / 0.716$ & 0.703 & 0.135 & 0.117 & 0.018 & 0.027 & 0.000 \\
\hline Emerging Share ${ }^{b}$ & $0.283 / 0.717$ & 0.745 & 0.137 & 0.078 & 0.020 & 0.000 & 0.020 \\
\hline NYSE Share ${ }^{b}$ & $0.296 / 0.704$ & 0.750 & 0.134 & 0.089 & 0.018 & 0.009 & 0.000 \\
\hline Nasdaq Share $^{b}$ & $0.259 / 0.741$ & 0.640 & 0.140 & 0.140 & 0.020 & 0.040 & 0.020 \\
\hline Age $(\text { weeks })^{c}$ & $1,045 / 952$ & 917 & 1,339 & 1,379 & 1,228 & 1,620 & 1,916 \\
\hline Market Cap $(\$ \text { bill })^{c}$ & $8,365 / 6,838$ & 8,246 & 3,854 & 10,867 & 8,406 & 14,089 & 1,793 \\
\hline
\end{tabular}

${ }^{a}$ Proportion out of number of firms rejecting no breaks beyond country level $=292{ }^{b}$ Under Breakers/Non-Breakers the ratio of firms that reject/don't reject, respectively, the hypothesis of no breaks over the number of firms by group Remaining columns report the ratio of the number of firms with cross-listing dates in a given time category over the number of firms rejecting the hypothesis of no break. ${ }^{c}$ Average per. 


\section{Table 5 Firm Characteristic Regressions for Break Events}

Table reports the coefficient estimates and standard errors for a multinomial logit regression where the dependent variable is the timing for Independent Breakers of the beta break date relative to the cross-listing date The dependent variable categories are: (a) cross-listing before first break confidence interval, "Before"; (b) crosslisting during one of the estimated break confidence intervals, "During"; or (c) cross-listing after any break-date confidence intervals, "After". The ommitted variable is (c). Panel A considers country information and company foreign sales variables. Panel B gives some geographics breakdowns and a bivariate logit regression for the probability of a firm being an Independent Breaker in the last three column.

\begin{tabular}{|c|c|c|c|c|c|c|c|c|}
\hline \multicolumn{9}{|c|}{ Panel A: Home Information and Company Sales Variables } \\
\hline \multirow[b]{2}{*}{ Timing from Cross-listing } & \multicolumn{2}{|c|}{ 1. Base Case } & \multicolumn{2}{|c|}{ 2. Pool Investors } & \multicolumn{2}{|c|}{ 3. Home Regulations } & \multicolumn{2}{|c|}{ 4. Foreign/Total Sales } \\
\hline & Before & During & Before & During & Before & During & Before & During \\
\hline \multirow[t]{2}{*}{ Constant } & $15.094^{* *}$ & 0.915 & $15.175^{* *}$ & 0.784 & $17.099^{* *}$ & 0.701 & $13.562^{* *}$ & 0.064 \\
\hline & $(2.881)$ & $(4.143)$ & $(2.861)$ & $(4.010)$ & $(3.242)$ & $(4.578)$ & $(3.1363)$ & $(4.459)$ \\
\hline \multirow[t]{2}{*}{ Age } & $-1.911^{* *}$ & 0.021 & $-1.892^{* *}$ & -0.016 & $-2.141^{* *}$ & 0.051 & $-1.726^{* *}$ & 0.180 \\
\hline & $(0.420)$ & $(0.605)$ & $(0.421)$ & $(0.603)$ & $(0.458)$ & $(0.648)$ & $(0.461)$ & $(0.648)$ \\
\hline \multirow[t]{2}{*}{ Market Cap Mean } & -0.050 & -0.207 & -0.016 & -0.178 & -0.074 & -0.209 & -0.006 & -0.194 \\
\hline & $(0.106)$ & $(0.140)$ & $(0.106)$ & $(0.139)$ & $(0.110)$ & $(0.143)$ & $(0.121)$ & $(0.160)$ \\
\hline \multirow[t]{2}{*}{ Pool Investors } & & & $-0.868^{* *}$ & -0.539 & & & & \\
\hline & & & $(0.397)$ & $(0.544)$ & & & & \\
\hline \multirow[t]{2}{*}{ Home Regulations } & & & & & $-0.860^{* *}$ & 0.079 & & \\
\hline & & & & & $(0.476)$ & $(0.639)$ & & \\
\hline \multirow[t]{2}{*}{ Foreign/Total Sales } & & & & & & & -0.306 & -0.613 \\
\hline & & & & & & & $(0.414)$ & $(0.566)$ \\
\hline Ho: All Coeff $=0$ & \multicolumn{2}{|c|}{$<0.000$} & \multicolumn{2}{|c|}{$<0.000$} & \multicolumn{2}{|c|}{$<0.000$} & \multicolumn{2}{|c|}{$<0.000$} \\
\hline
\end{tabular}


Table 5 Firm Characteristic Regressions for Break Events (cont.)

\begin{tabular}{|c|c|c|c|c|c|c|c|c|}
\hline \multicolumn{9}{|c|}{ Panel B: Geographic Differences } \\
\hline \multirow[b]{2}{*}{ Timing from Cross-listing } & \multicolumn{2}{|c|}{ 1. Emerging } & \multicolumn{2}{|c|}{$2 \mathrm{~N}$ America } & \multicolumn{2}{|c|}{ 3.Canada } & \multicolumn{2}{|c|}{ 4. Independent Breakers } \\
\hline & Before & During & Before & During & Before & During & N. America & Mexico \\
\hline \multirow[t]{2}{*}{ Constant } & $16.720^{* *}$ & 0.872 & $14.873^{* *}$ & 0.599 & $15.053^{* *}$ & 0.679 & $-2.310^{*}$ & $-2.277^{*}$ \\
\hline & $(3.232)$ & $(4.565)$ & $(2.871)$ & $(4.075)$ & $(2.879)$ & $(4.098)$ & $(1.188)$ & (1.187) \\
\hline \multirow[t]{2}{*}{ Age } & $-2.095^{* *}$ & 0.026 & $-1.983^{* *}$ & 0.033 & $-1.984^{* *}$ & 0.025 & $0.289^{* *}$ & 0.247 \\
\hline & $(0.453)$ & $(0.642)$ & $(0.425)$ & $(0.600)$ & $(0.425)$ & $(0.604)$ & $(0.177)$ & $(0.176)$ \\
\hline \multirow[t]{2}{*}{ Market Cap Mean } & -0.072 & -0.207 & 0.012 & -0.182 & -0.005 & -0.186 & 0.013 & 0.036 \\
\hline & $(0.109)$ & $(0.143)$ & $(0.108)$ & $(0.138)$ & $(0.107)$ & $(0.139)$ & $(0.047)$ & $(0.046)$ \\
\hline \multirow[t]{2}{*}{ Emerging } & -0.642 & 0.038 & & & & & & \\
\hline & $(0.471)$ & $(0.643)$ & & & & & & \\
\hline \multirow[t]{2}{*}{ North America } & & & $1.470^{* *}$ & 0.414 & & & & \\
\hline & & & $(0.655)$ & $(0.877)$ & & & & \\
\hline \multirow[t]{2}{*}{ Canada } & & & & & $1.332^{* *}$ & 0.445 & $-0.472^{* *}$ & \\
\hline & & & & & $(0.657)$ & & $(0.212)$ & \\
\hline \multirow[t]{2}{*}{ Mexico } & & & & & & & & $-1.049^{* *}$ \\
\hline & & & & & & & & $(0.507)$ \\
\hline Ho: All Coeff $=0$ & \multicolumn{2}{|c|}{$<0.000$} & \multicolumn{2}{|c|}{$<0.000$} & $<0.000$ & $<0.000$ & $<0.000$ & $<0.000$ \\
\hline
\end{tabular}

** Significant at $95 \%$ confidence level ${ }^{*}$ Significant at $90 \%$ confidence level. Standard errors in parentheses. 


\section{Table 6 Break Dates and Market Liberalizations}

This table reports the first break dates estimated for emerging markets in the sample along with estimates from Bekaert, Harvey, and Lumbsdaine (2002), labeled BHL, and the Official Liberalization Date from Bekaert and Harvey (2000). Break dates are estimated using the Sup(F) Test for trimming constraint $\varepsilon$.

\begin{tabular}{|l|c|c|c|c|c|c|}
\hline \multicolumn{1}{|c|}{ Country } & $\begin{array}{c}\text { 1. Break Date } \\
\text { for } \varepsilon=5 \%\end{array}$ & $\begin{array}{c}\text { 2. Break Date } \\
\text { for } \varepsilon=15 \%\end{array}$ & $\begin{array}{c}\text { 3. Series } \\
\text { Start Date }\end{array}$ & $\begin{array}{c}\text { 4. BHL } \\
\text { Overlap }^{a}\end{array}$ & $\begin{array}{c}\text { 5. BHL } \\
\text { Estimate }^{b}\end{array}$ & $\begin{array}{c}\text { 6. Official } \\
\text { Liberalization }^{c}\end{array}$ \\
\hline Argentina & Jan-99 & Jan-99 & Aug-93 & 2.4 & Jun-92 & Nov-89 \\
Brazil & Oct-02 & Oct-02 & Jul-94 & 1.5 & Apr-90 & May-91 \\
Chile & Jan-91 & Jan-94 & Jul-89 & 6.4 & Jan-93 & Jan-92 \\
Greece & Oct-03 & Oct-03 & Mar-92 & 3.8 & May-94 & Feb-91 \\
India & Feb-06 & Feb-06 & Jan-90 & 6.0 & Aug-90 & Dec-87 \\
Korea & Apr-00 & Apr-00 & Jan-90 & 6.0 & May-93 & Nov-92 \\
Mexico & Sep-97 & Sep-97 & Sep-87 & 8.3 & Sep-88 & Jan-92 \\
Portugal & Nov-04 & Nov-04 & Jan-73 & 23.0 & Jan-92 & May-89 \\
Taiwan & Nov-05 & Nov-05 & Jun-94 & 1.6 & Jun-88 & Jul-86 \\
Turkey & May-90 & Sep-01 & Jan-90 & 6.0 & Oct-88 & Jan-91 \\
Venezuela & Oct-00 & Oct-00 & Aug-93 & 2.4 & May-89 & Aug-89 \\
\hline
\end{tabular}

${ }^{a}$ Number of years that series overlaps with BHL sample from January 1976 to December 1995

${ }^{b}$ Estimates from BHL Table 3 for Quadrivariate Model ${ }^{c}$ From Bekaert and Harvey (2000) 


\section{Table 7 U.S. Investor Minimum Variance Portfolio Implications}

Table reports the properties of the minimum variance portfolio of U.S.investors holding the US market portfolio and a portfolio of stocks from foreign companies listed in the US market in 2004. Panel A assumes the foreign stocks are investable for US investors once they are llisted in their home markets. Panel B assumes these stocks become investable only after they are listed in the U.S. market. Panel $\mathrm{C}$ corresponds to the same assumption about investability as Panel $\mathrm{B}$, but further estimates betas with the finer trimming parameter of $\epsilon=5 \%$

\begin{tabular}{|c|c|c|c|c|c|}
\hline \multicolumn{6}{|c|}{ Panel A: Foreign Firms are Investable Upon Home-Listing } \\
\hline & $1970 \mathrm{~s}$ & $1980 \mathrm{~s}$ & $1990 \mathrm{~s}$ & $2000 \mathrm{~s}$ & $2000 \mathrm{~s}$ \\
\hline Short Sale Constraint? & NA & NA & NA & Yes & No \\
\hline Decline in Portfolio StDev in \% & 3.24 & 1.49 & 1.63 & 0.02 & 3.30 \\
\hline Decline as $\%$ of US Market StDev & 19.60 & 9.04 & 9.88 & 0.11 & 19.99 \\
\hline Portfolio Share in Foreign Stocks & 0.96 & 0.75 & 0.92 & 0.04 & -0.65 \\
\hline \multicolumn{6}{|c|}{ Panel B: Foreign Firms are Investable Upon US-Listing } \\
\hline & $1970 \mathrm{~s}$ & $1980 \mathrm{~s}$ & $1990 \mathrm{~s}$ & $2000 \mathrm{~s}$ & $2000 \mathrm{~s}$ \\
\hline Short Sale Constraint? & NA & NA & NA & Yes & No \\
\hline Decline in Portfolio StDev in \% & 1.44 & 0.53 & 0.48 & 0.00 & 3.35 \\
\hline Decline as $\%$ of US Market StDev & 8.72 & 3.21 & 2.92 & 0.00 & 20.28 \\
\hline Portfolio Share in Foreign Stocks & 0.47 & 0.34 & 0.49 & 0.00 & -0.71 \\
\hline \multicolumn{6}{|c|}{ Panel C: Betas Estimated with Trimming $\epsilon=5 \%$} \\
\hline & 1970s & $1980 \mathrm{~s}$ & $1990 \mathrm{~s}$ & $2000 s$ & $2000 \mathrm{~s}$ \\
\hline Short Sale Constraint? & NA & NA & NA & Yes & No \\
\hline Decline in Portfolio StDev in \% & 1.83 & 0.47 & 0.31 & 0.00 & 2.69 \\
\hline Decline as $\%$ of US Market StDev & 11.06 & 2.85 & 1.88 & 0.00 & 16.31 \\
\hline Portfolio Share in Foreign Stocks & 0.49 & 0.26 & 0.40 & 0.00 & -0.74 \\
\hline
\end{tabular}




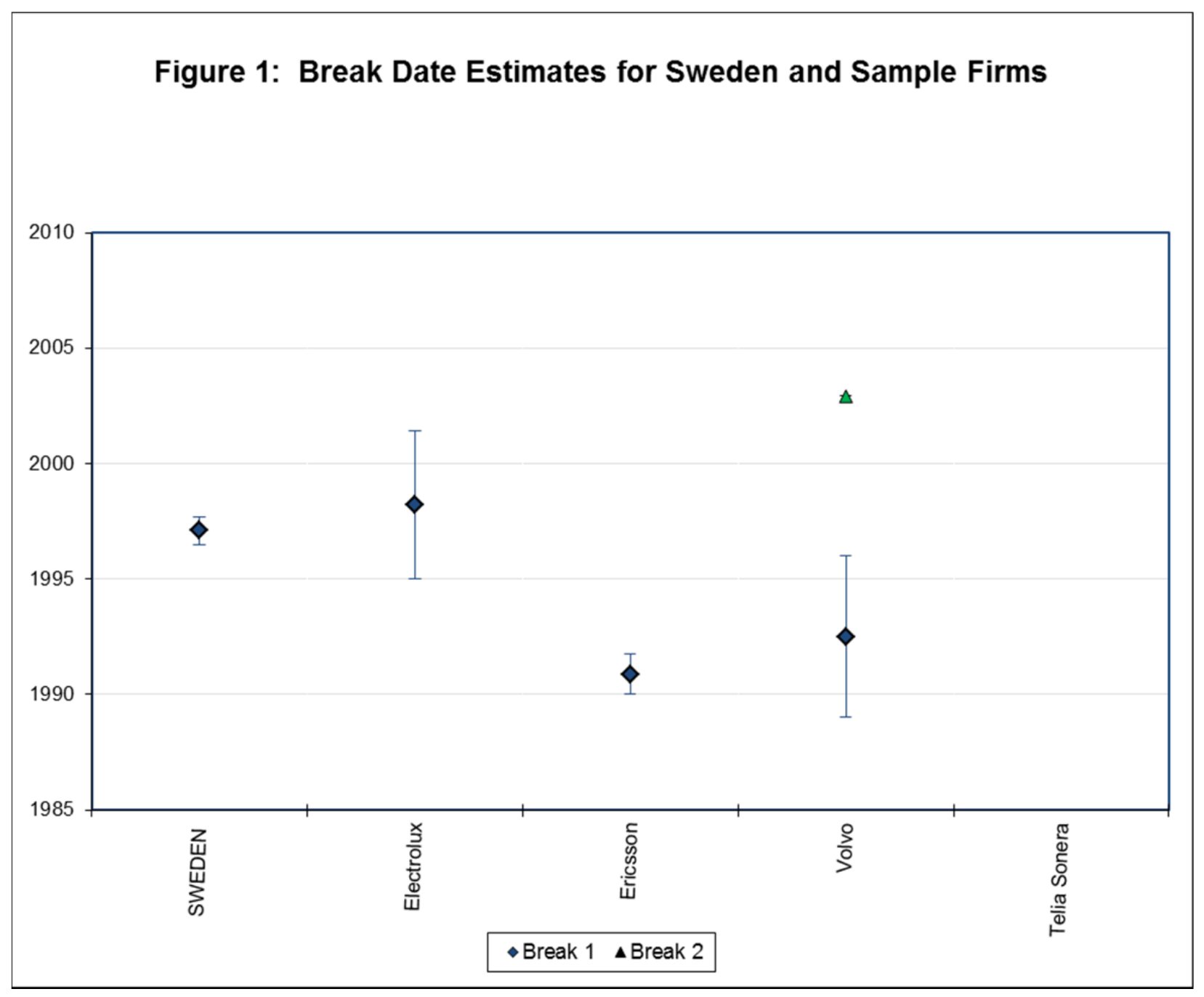

This figure plots estimated break dates for equity returns against the US market with markers and their $90 \%$ confidence intervals with error bars. The break date estimates are plotted for the aggregate Swedish market ("SWEDEN") and for three Swedish companies that are cross-listed in the US market: Electrolux, Ericsson, and Volvo. The figure also depicts the case of Talia Sonera, a Swedish company with no statistical evidence of a break against the US market. 


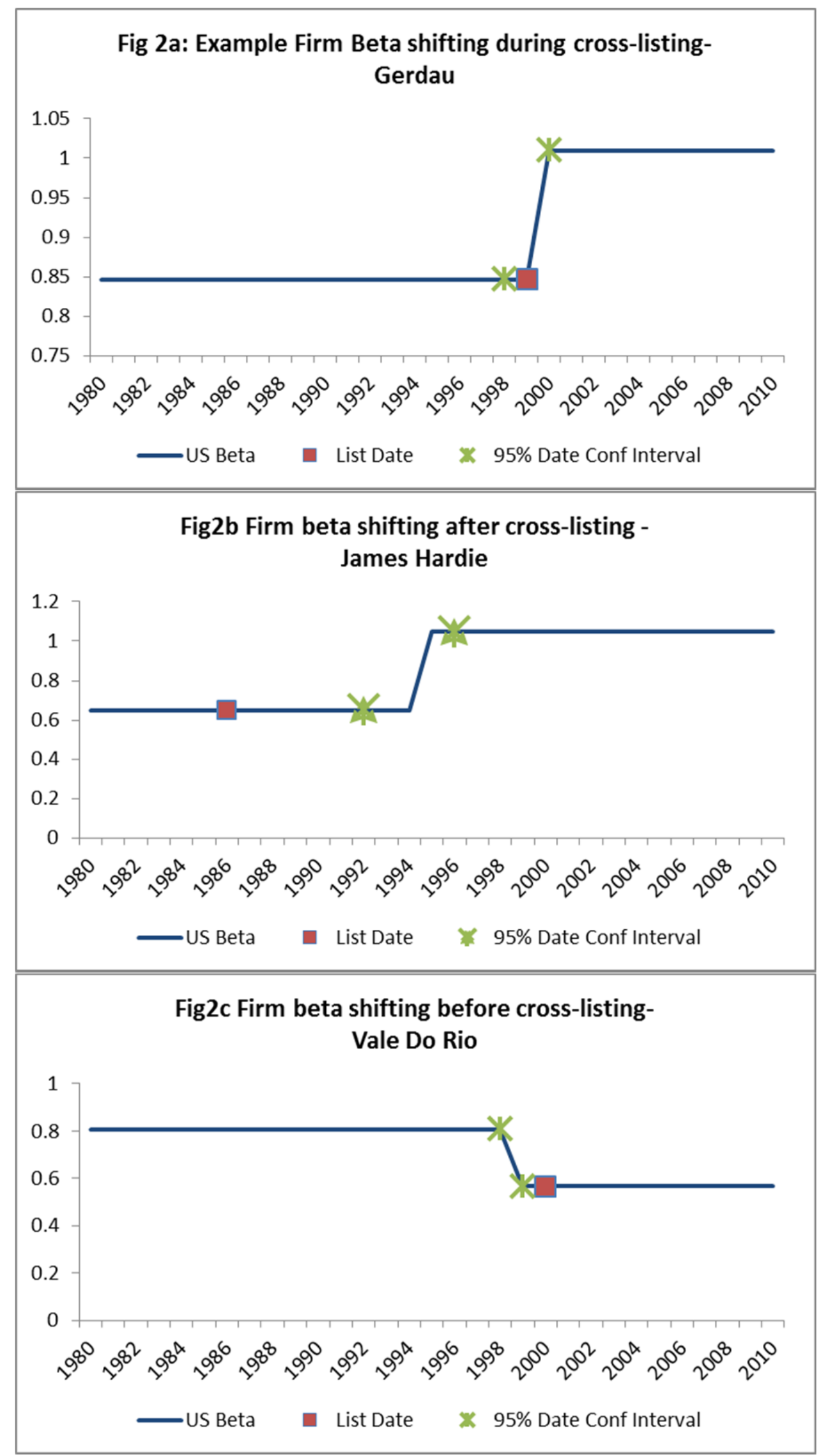

Figure plots evolution of beta and break date estimates for three companies using techniques described in Section 1. Break date confidence intervals indicated by starred triangles. Cross-listing dates indicated by rectangles. 


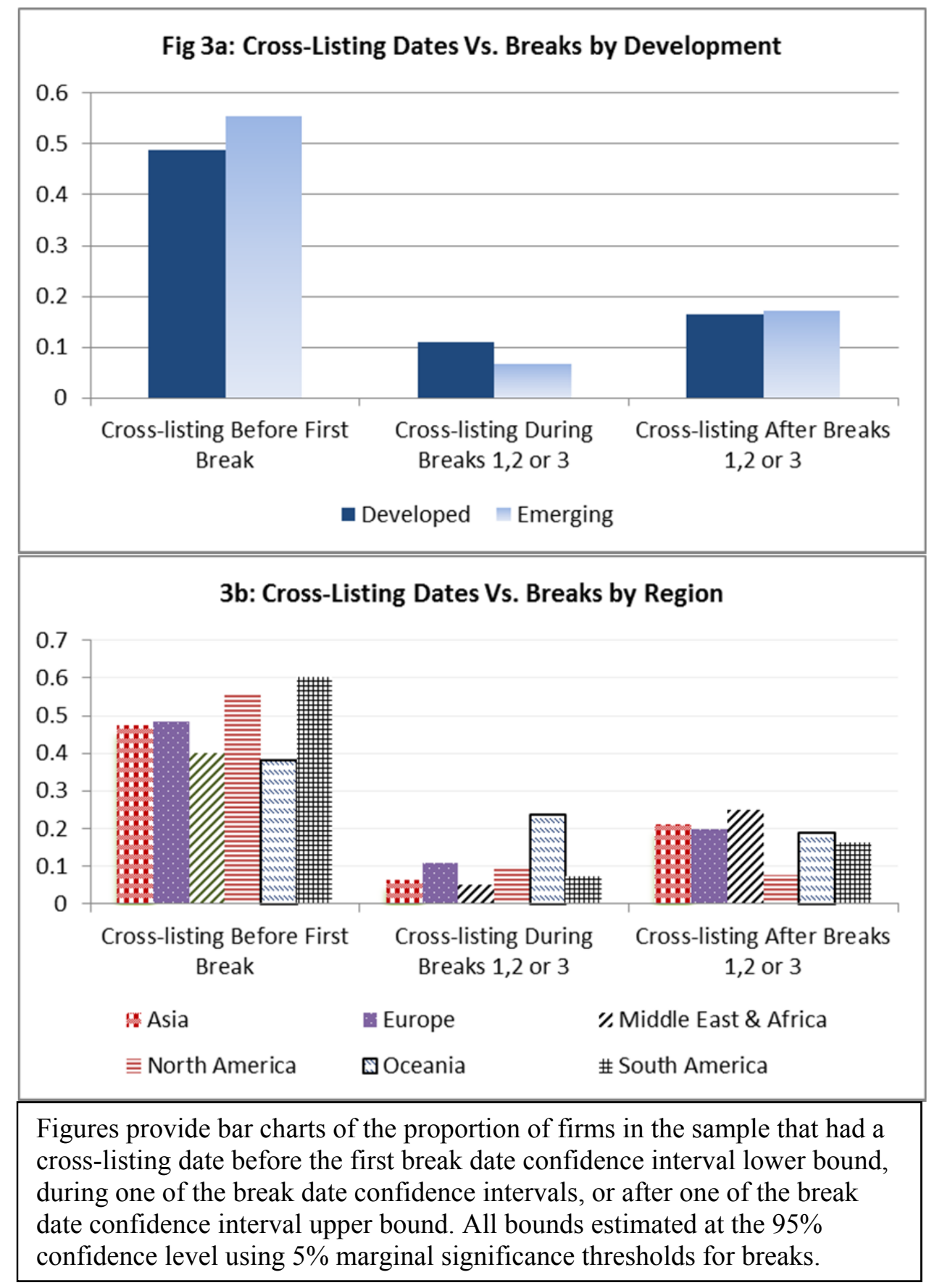


Figure 4: Break Date Estimates by Country

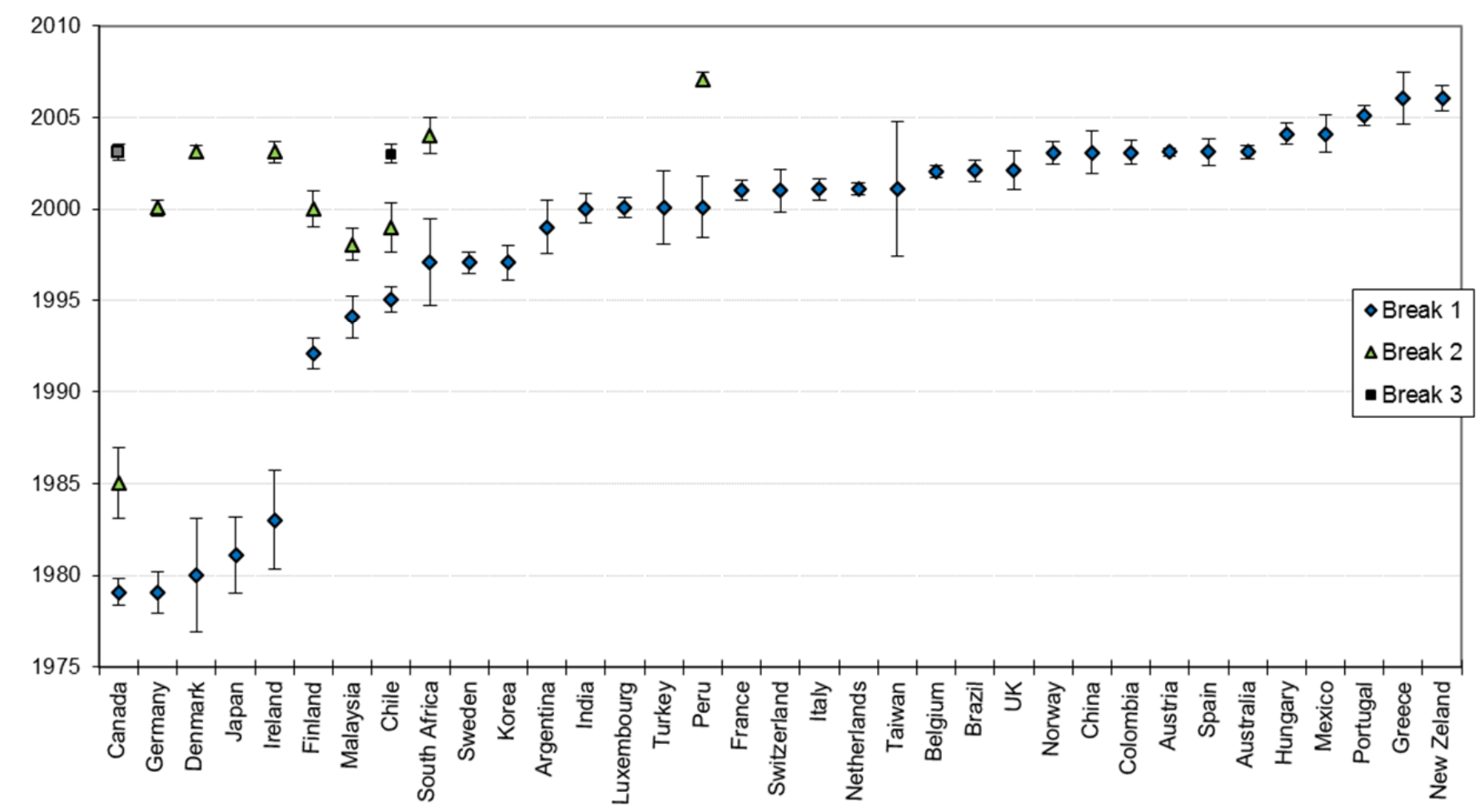

Figure plots estimated break dates for country return parameters. Error bands depict confidence intervals for highest $95 \%$ and lowest $5 \%$ dates. 


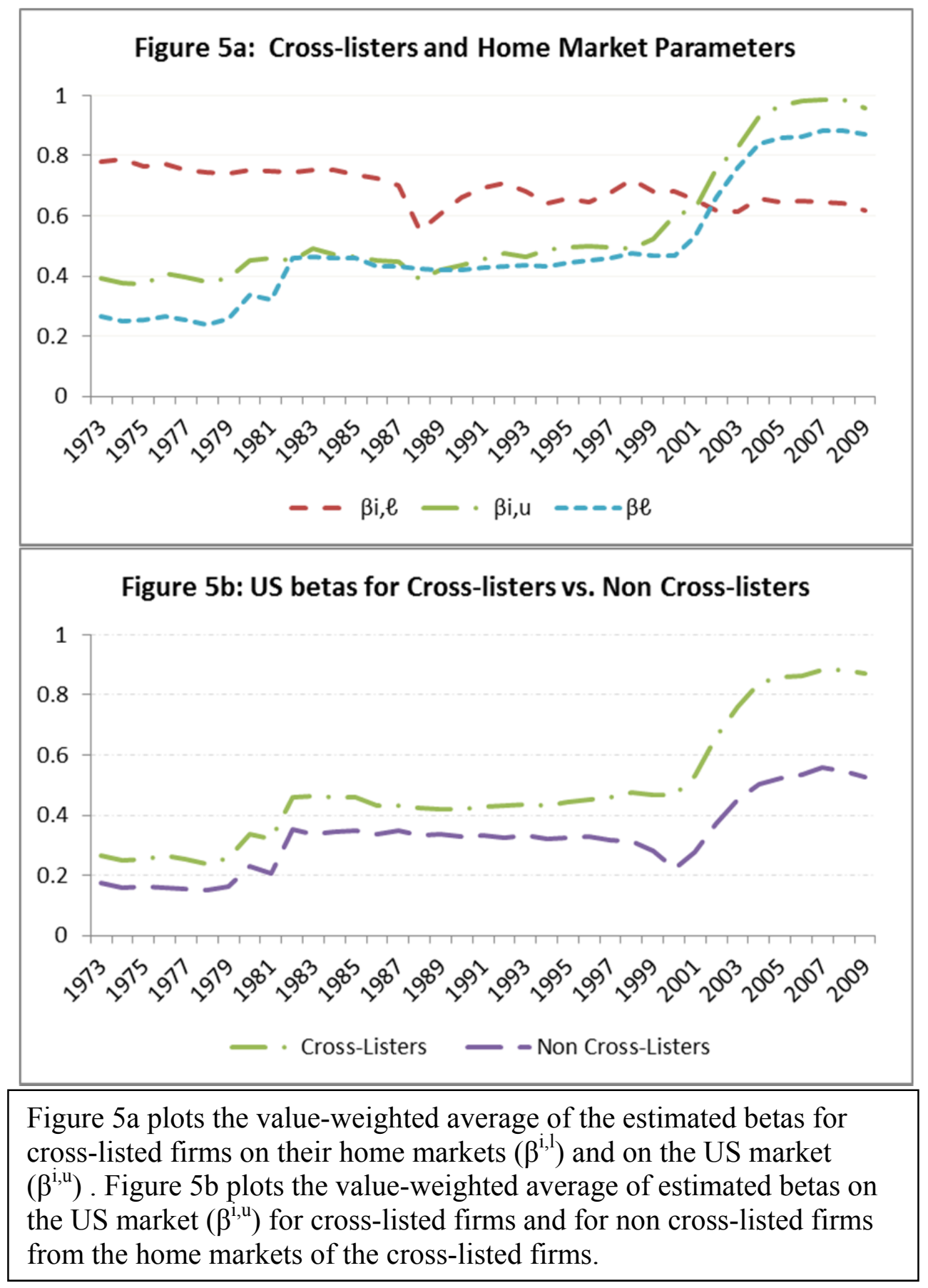




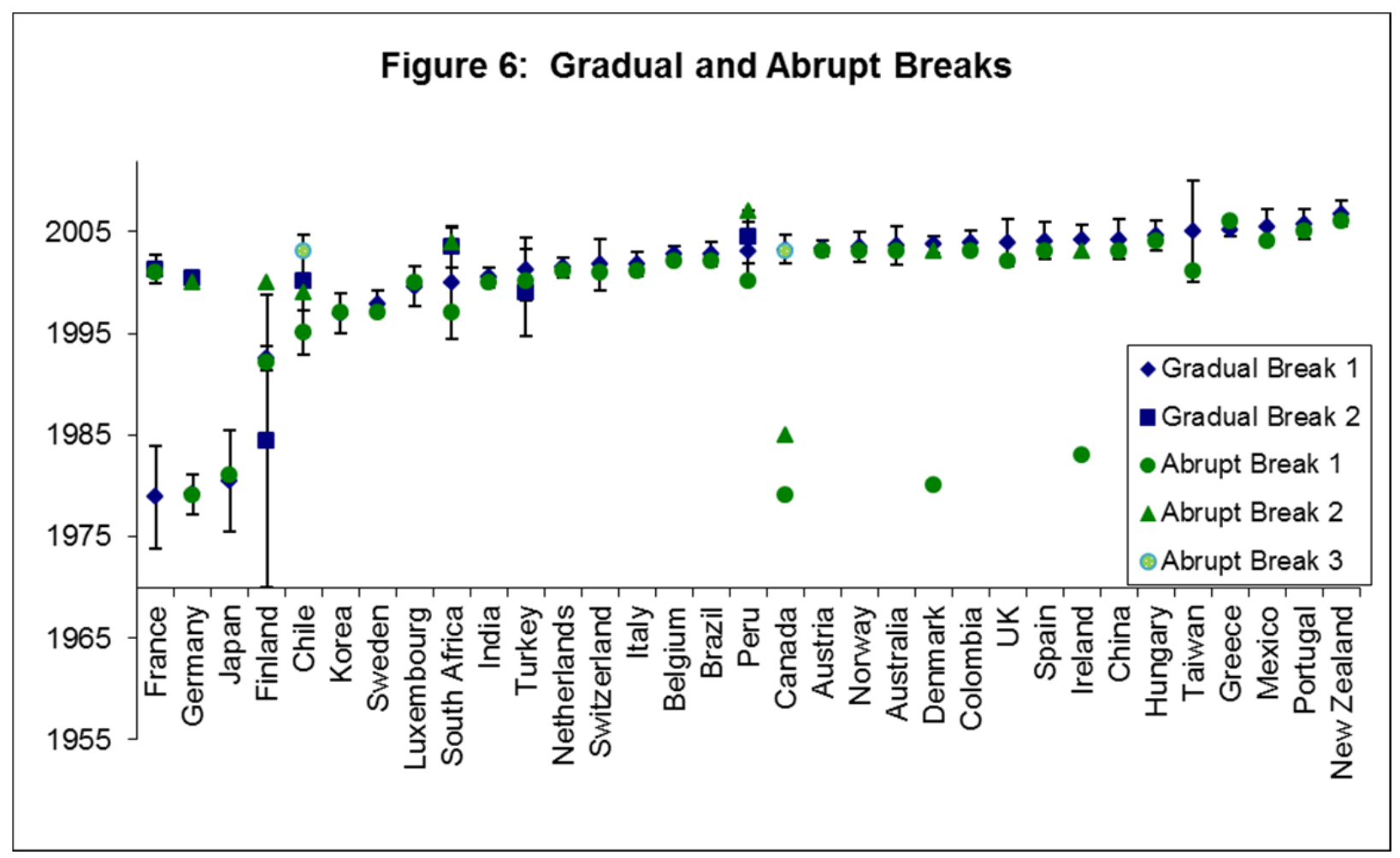

Figure plots estimated break dates for country return parameters, comparing abrupt break estimates as in Figure 4 and gradual breaks assuming residuals autocorrelation. Error bands depict confidence intervals for highest $95 \%$ and lowest $5 \%$ dates. 